\title{
Myocardial Reprogramming Medicine: The Development, Application, and Challenge of Induced Pluripotent Stem Cells
}

\author{
Yigang Wang \\ Departments of Pathology and Laboratory Medicine, College of Medicine, University of Cincinnati Medical Center, \\ 231 Albert Sabin Way, Cincinnati, OH 45267-0529, USA
}

Correspondence should be addressed to Yigang Wang; yi-gang.wang@uc.edu

Received 16 January 2014; Revised 1 April 2014; Accepted 2 April 2014; Published 16 June 2014

Academic Editor: Stefan Liebau

Copyright (C) 2014 Yigang Wang. This is an open access article distributed under the Creative Commons Attribution License, which permits unrestricted use, distribution, and reproduction in any medium, provided the original work is properly cited.

Induced pluripotent stem cells (iPSCs) can be generated by reprogramming of adult/somatic cells. The somatic cell reprogramming technology offers a promising strategy for patient-specific cardiac regenerative medicine, disease modeling, and drug discovery. iPSCs are an ideal potential option for an autologous cell source, as compared to other stem/progenitor cells, because they can be propagated indefinitely and are able to generate a large number of functional cardiovascular cells. However, there are concerns about the specificity, efficiency, immunogenicity, and safety of iPSCs which are major challenges in current translational studies. In order to bring iPSC technology closer to clinical use, fundamental changes in this technique are required to ensure that therapeutic progenies are functional and nontumorigenic. It is therefore critical to understand and investigate the biology, genetic, and epigenetic mechanisms of iPSCs generation and differentiation. In this spotlight paper the discovery, history, and relative mechanisms of iPSC generation are summarized. The current technological improvements and potential applications are highlighted along with the important challenges and perspectives. Finally, emerging technologies are presented in which improvements to iPSC generation and differentiation approaches might warrant further investigation, such as integration-free approaches, direct reprogramming, and the development of iPSC banking.

\section{Introduction}

Myocardial infarction (MI) is an important manifestation of coronary artery disease (CAD) and major cause of death and disability worldwide. MI occurs when prolonged ischemia irreversibly destroys distal blood vessels and myocardium, causing apoptosis or cell death, eventually triggering cardiac remodeling or sudden death $[1,2]$. Recurrent MI leads to chronic postinfarct heart failure in patients with a longer life span. Currently, traditional therapeutic approaches focus on limitation of the initial injury and secondary maladaptive complications in order to prevent the death of existing myocardium. Despite significant advances in medical treatments over the past decades, chronic heart failure remains as a leading cause of death $[3,4]$. Indeed, heart transplantation is the only available viable therapeutic option for end-stage heart failure, but this option is limited by the paucity of matched donor tissue specimens and by the requirement for life-long treatment with immunosuppresive agents.
Regenerative therapies offer great promise for patients with heart disease by using angiomyogenesis to create a source of replacement for lost or damaged cardiac tissues associated with MI [3,4]. Therefore, a pivotal current task is to obtain ideal pluripotent stem/progenitor cells with cardiovascular potential. These characteristics include but are not limited to safety, sufficient quantity and quality for clinical applications, stable capacity of self-renew and differentiation, low immunogenicity, and a minimization of any ethical issues.

First seen in studies of experimental embryology, mouse or human embryonic stem cells (ESCs) were discovered as a kind of pluripotent stem cells derived from the inner cell mass of a developing blastocyst. A great milestone in stem cell biology occurred when it was found that these cells could be propagated in culture in an undifferentiated state [5-7]. Multiple studies have since demonstrated that ESCs can differentiate into all the cell lineages of the embryo, fetus, and adult under defined conditions [8-10]. ESCs can be 
propagated indefinitely and serve as a potentially inexhaustible supply of functional cardiomyocytes under defined differentiation conditions. Although ethical issues and teratoma formation potentially hinder the clinical application of ESCs, they are important and useful tools for cell-line models of pluripotency (stemness) in both basic research and clinical medicine [11]. For decades, there has been tremendous enthusiasm in the quest to identify the master regulators of pluripotency (or totipotency) from investigating ESCs [12, 13]. Various signaling pathways were found to modulate the pluripotency and function of ESCs both in vivo and in vitro, as summarized in other reviews [11, 14]. Large scale gene expression profiling was performed to identify the regulators controlling pluripotency and lineage specificity in ESCs [13, 15]. Notably, it was found that the pluripotency and selfrenewal of ESCs are maintained by a network of transcription factors (TFs), such as octamer-binding transcription factor4 (Oct4), signal transducer and activator of transcription 3 (Stat3), and homeobox transcription factor Nanog [16, 17].

The technique of somatic cell nuclear transfer (SCNT) was established during the 1950s to probe the developmental potential of nuclei by transplanting them into enucleated oocytes $[18,19]$. SCNT studies demonstrated that differentiated cells or somatic cells retain all of the genetic information in nuclei as early embryonic cells, which are required for the entire organism development. In these trials, the nucleus of oocyte was exchanged with the genome of a somatic cell using SCNT technology to generate pluripotent stem cells for regenerative applications [20]. Stem cell lines derived from these artificial blastocysts were capable of differentiation into cell types of all three germ layers. However, this reprogramming approach requires private egg donation from women and the support of ethical policies [21]. Thus, this approach is technically challenging and ethically questionable and therefore not suitable for translational research $[22,23]$. A hypothesis arose that a combination of master regulators or factors isolated from nuclei can reprogram somatic cells (nonpluripotent cells) back into the embryonic state of pluripotency. This procedure of changing cell phenotypes is referred to as "reprogramming". Thus, the transfer of TFs which are the dominating active proteins in nuclei could be an alternative reprogramming strategy.

Initially, Yamanaka showed that stem cells with properties similar to ESCs could be generated from mouse or human fibroblasts by simultaneously introducing four TFs [24, 25]. Thomson subsequently reported the generation of novel human stem cells using a different combination of factors [26]. These novel stem cells were designated as induced pluripotent stem cells (iPSCs). The iPSC technology using adult somatic cells avoids the ethical issues raised in ESCs. In addition, the differentiation of iPSCs into functional cells is beneficial for cell based therapy and also plays an important role in the establishment of patient-specific disease models for drug discovery and development. The simplicity and reproducibility of iPSC technology have increased interest for their usage in regenerative medicine. In this spotlight article, I summarize the generation and potential application of iPSCs, as well as the major challenges, highlights, progress, and future directions.

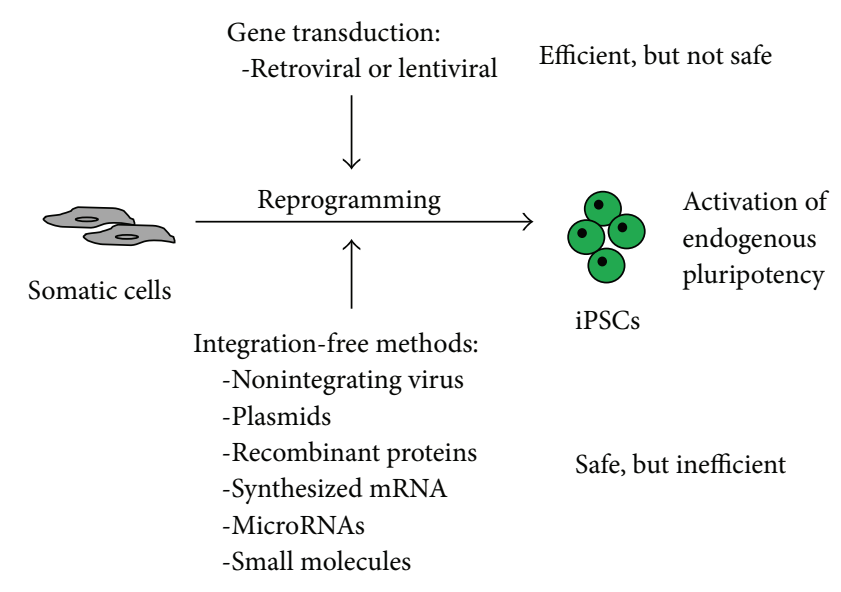

FIGURE 1: The current approaches of iPSC generation. There are a number of different approaches for iPSC generation from somatic cell reprogramming, including gene transduction and integrationfree methods. Retroviral or lentiviral gene transduction is the most efficient and widely used method, but the integration of TFs into a host genome increases the concerns of oncogenicity and mutagenesis. The integration-free methods include using nonintegrating virus, plasmids, recombinant proteins, synthesized mRNA, microRNAs, and small molecules. Most of these approaches are safe, but reprogramming efficiency is lower than that of gene integration. The activation of endogenous pluripotency is considered an important criterion of high-quality fully reprogrammed iPSCs.

\section{Generation of iPSCs}

In order to efficiently produce iPSCs as research tools, and ultimately translate laboratory results into clinical applications, a number of different somatic cell reprogramming approaches have been developed, including gene transduction and integration-free methods (Figure 1).

\subsection{Gene Transduction}

2.1.1. Cell Transfection. Gene transduction can be used to generate iPSCs using retroviral or lentiviral approaches, which are currently the most efficient and widely used methods, although progress is rapidly growing in the use of other gene delivery methods. Twenty four pluripotencyassociated candidate genes were initially evaluated in an assay system by retroviral transduction in order to identify the effective reprogramming factors. After successive elimination of individual factors, the minimal four genes comprising Oct4, Klf4, Sox2, and c-Myc (OSKM) were determined to induce reprogramming of mouse embryonic fibroblasts (MEFs) [25]. This method of iPSC production has many advantages, not only because the biological properties are similar to ESCs, but also because there are no ethical and legal issues and they are technically more feasible. Several laboratories began to use, reproduce, and improve the procedure of modifying the combination of different reprogramming factors or expanding the selection of target adult cells [22, 27]. In addition to OSKM genes, other core pluripotency genes such as Nanog and Lin 28 were also determined as efficient 
reprogrammers of human fibroblasts into pluripotent cells $[26,28]$.

As the reprogramming approaches rise in number, it is important to generate optimal reprogramming factor cocktails for various adult cells. Each protocol must take into consideration the reprogramming efficiency because currently it is at a very low level in the majority of current studies (typically much less than 1\% [22]). This means that the reprogramming process of most transfected cells is never completed. Moreover, there is great variability in the quality of iPSC clones, even when using the same protocol. This variability is probably attributable to a multitude of complicated events, including gene delivery methods, growth conditions, culture timing, target cell selection, and stochastic genetic integration. Hematopoietic stem and progenitor cells were reported as an attractive cell resource to generate iPSCs with efficiency of up to $28 \%$, as compared to terminally differentiated $\mathrm{B}$ and $\mathrm{T}$ cells [29]. The modification of cell culture conditions and the addition of molecular compounds also proved to enhance the reprogramming efficiency [30,31].

Of great concern in these protocols is safety, as many reprogramming factors can be linked with the pathophysiology of cancer, such as c-Myc which is a very strong protooncogene $[32,33]$. To decrease the risk of teratoma formation in the future applications, often genes can be replaced by other members of the same family. For instance, L-Myc or NMyc can substitute for c-Myc [34]. This simple elimination of c-Myc in iPSCs eliminated the development of tumors during the study period, albeit with a decreasing reprogramming efficiency [35]. This low-efficiency issue, however, was minimized by using a modified low-serum culture protocol to obtain high quality iPSCs [36]. Poly (ADP-ribose) polymerase-1 was also found to act as a replacement for $\mathrm{c}-\mathrm{Myc}$ or Klf4 and enhanced the efficiency of iPSC generation [37]. Nuclear reprogramming independent of c-Myc (using Sox2, Oc4, and Klf4) enhanced the innate cardiogenic potential of pluripotent stem cells, with the observation of consistent beating activity, sarcomere maturation, and rhythmical intracellular calcium dynamics [38].

In a different example, a detailed protocol was developed to derivate iPSCs from cord blood stem cells using retroviral transduction with only two factors (Oct4 and Sox2) that are a prerequisite in the majority of present studies [39]. However, the latest study shows that Oct 4 and Sox 2 can be replaced by some identified factors completely (Gata3 for Oct4; ZNF521, OTX2, and PAX6 for Sox2) to induce the reprogramming of human fibroblasts [40]. It has also been found that Oct4 and its substitutes (Gata3, HNF4a, and GRB2, etc.) are involved in mesendodermal specification, while Sox2 and its substitutes (Sox1, RCOR2, and GMNN, etc.) are involved in ectodermal specification regulating the balance of pluripotency and differentiation [41]. DNA hydroxylase Tet1 can replace Oct4 by promoting Oct4 demethylation and reactivation to initiate somatic cell reprogramming [42]. These studies indicate that all reprogramming factors are potentially interchangeable, which increases the feasibility and flexibility in the manipulation and improvement of iPSCs generation.
2.1.2. Inducible Transduction. As discussed above, the low efficiency of iPSC generation is a great challenge for the study of the molecular processes or mechanisms during the early phase of reprogramming. The use of an inducible transduction system, which can be flexibly controlled by the inert drug tetracycline (Tet) or doxycycline (Dox), allows for increasing efficiency and the selection of fully reprogrammed iPSCs [43]. This approach relies on the addition of Dox and is more convenient than the conventional methods which require de novo delivery of reprogramming genes into target cells. Lentiviral vectors can be used to generate iPSCs by encoding the four reprogramming factors and have high infection efficiency $[44,45]$. Lentiviral vectors can also be modified to establish an inducible transgene expression system for iPSC generation. Briefly, the system is established in target cells containing two main components, including expression of reverse-tetracycline-dependent transactivator (rtTA) and the corresponding inducible promoter controlling the expression of reprogramming genes (Figure 2(a)). The specific promoter lacks binding sites for endogenous TFs, so it is virtually silent in the absence of induction. In the presence of Tet or Dox, the transactivator binds tightly and specifically to the promoter and activates transcription of the downstream genes of interest [46].

To generate genetically homogeneous cell populations, primary somatic cells (such as hepatic cells, hematopoietic cells, or fibroblasts) can be infected with Dox-inducible lentivirus encoding OSKM to generate the "primary" iPS cell lines with Dox in culture medium [43, 47]. These can then be injected into blastocysts to create chimeras for the generation of "secondary" somatic cells that carry the reprogramming factors. These can then be isolated and generate new iPSCs by Dox induction (Figure 2(b)). This method of generating iPSCs was indirectly derived from gene transduction and is termed as "secondary" iPSCs (or secondary reprogramming systems) [48]. Reprogramming efficiency was radically improved by 25 - to 50 -fold greater efficiency than using "primary" iPSC generation techniques [43]. However, the production of "secondary" somatic cells from chimeras is tedious and expensive.

Current studies are seeking an even more ideal resource of "secondary" somatic cells. Using "primary" iPSCs generated from primary human fibroblasts and keratinocytes with the Dox-inducible system, cells can be differentiated into fibroblast-like cells as the "secondary" somatic cells (Figure 2(b)). These can finally be used to produce "secondary" iPSCs using Dox treatment, resulting in an even higher efficiency ( 100 -fold greater than the initial conversion) [49]. It was also reported that up to $2 \%$ of the "secondary" human fibroblasts derived from primary iPSCs were reprogrammed to "secondary" iPSCs using this system [50]. This provides a powerful and efficient platform for studying the underlying molecular mechanisms during reprogramming as well as for screening chemical and genetic factors that enhance or block reprogramming.

Unfortunately retroviral transgenes are epigenetically silenced towards the end of reprogramming $[51,52]$. Consequently, the partially reprogrammed cells are dependent on exogenous factors and can fail to activate the corresponding 


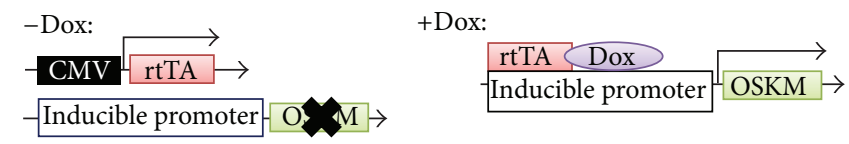

(a)

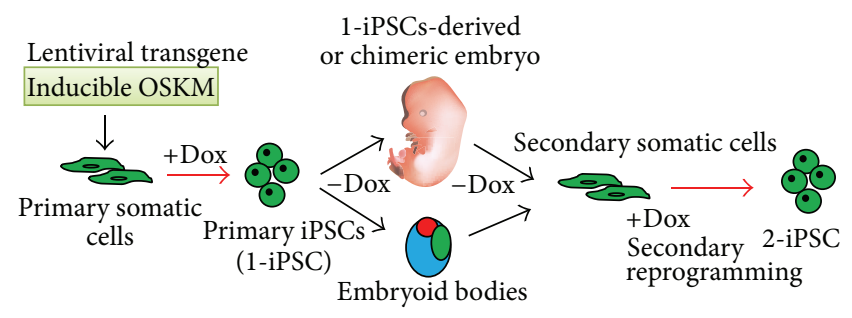

(b)

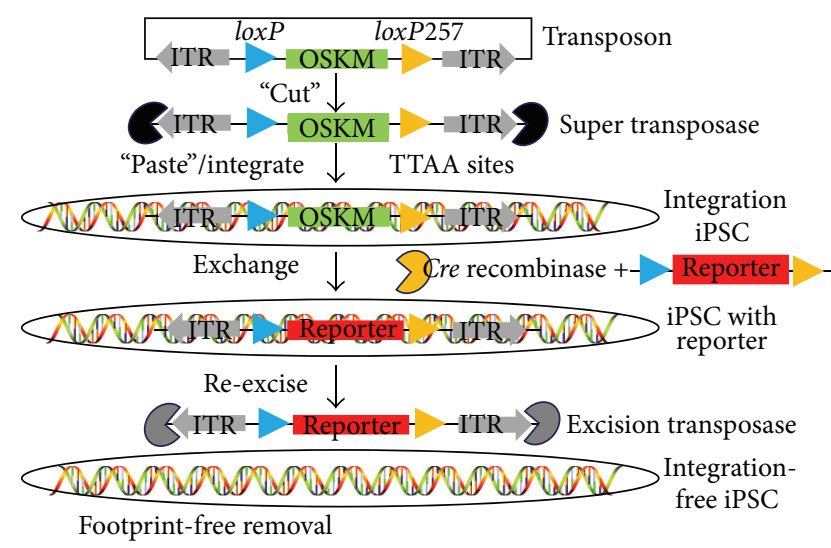

(c)

FIgURE 2: The inducible transgene and excisable system for iPSC generation. (a) The inducible transgene system conta ins two main components, reverse-tetracycline-dependent transactivator (rtTA) and the inducible promoter controlling the expression of reprogramming genes (OSKM). In the absence of doxycycline (Dox) induction, the specific promoter lacks binding sites for endogenous TFs, so it is virtually silent. In the presence Dox, the transactivator binds tightly and specifically to the promoter and activates transcription of OSKM genes. (b) The primary somatic cells (such as fibroblasts) were infected with inducible lentivirus encoding OSKM to generate "primary" iPSCs (1-iPSCs) with Dox. These were then injected into blastocysts to create chimeras or formed into embryoid bodies for the generation of "secondary" somatic cells. These then carry the inducible reprogramming factors, which were isolated and used to generate secondary iPSCs (2-iPSCs) using Dox induction. (c) The schematic of integration-free iPSCs generated by the transposon and Cre-loxP excisable system. The OSKM cassette was flanked by compatible loxP-loxP257 sites and inserted between the specific inverted terminal repeat (ITR) sequences of transposon vector. The insertion was excised ("cut") by hyperactive transposase from ITR to integrate ("paste") into the TTAA sites of chromosomal DNA in transfected somatic cells. After integration-iPSC generation, the reporter tracking gene (such as RFP) can be introduced by Cre recombinase which can specifically recognize loxP sites, resulting in the removal of OSKM. Finally, the integrated fragment can be re-excised by excision transponsase to generate integration-free iPSCs.

endogenous genes $[22,53]$. This issue becomes exacerbated when lentiviral vectors are used and subjected to variable levels of silencing causing a differentiation block [54, 55]. Although viral transgene approaches were adequate for initial studies, current research requires more precise tools to explore deeper into the events and mechanisms underlying reprogramming, in particular for in vivo study [56].

Recently, double transgenic reprogrammable mouse systems have been developed as the most advanced techniques in mouse inducible iPSC generation. After a generation of "primary" iPS cells are generated using the inducible system, cells were used to breed chimeric mice whose somatic cells could be isolated and reprogrammed in vitro by addition of Dox [57]. This study also compared the reprogramming efficiencies among MEF lines containing different combinations of a defined set of Dox-inducible proviral genomes, providing a unique platform for identifying components that can substitute for a given reprogramming factor. However, it was difficult for the random segregation of multiple transgenes to maintain all factors in one mouse and identification of the genotype was needed for offspring in each generation. This limitation was alleviated by using inducible collagen type I (Colla1) locus-targeted transgenic mouse models as described in two back-to-back publications [58, 59]. Different 
strategies were used to link the four reprogramming genes (OSKM) in one vector under the control of the Doxinducible promoter. The various somatic cell types from their offspring (any embryonic, fetal, or adult tissue) allowed iPSC generation with Dox treatment. Breeding is effective, but most importantly no tumors or other health problems were detected in these offspring. A line of conditional, inducible, and exchangeable "reprogrammable mice" was established for studying cellular (de)differentiation [60]. This mouse model can realize tissue or cell-specific expression and is also a means of selecting OSKM-expressing cells, allowing for the exchange of the reprogramming factors by other genes at a defined locus. These reprogrammable mice have emerged as an excellent in vivo tool for studying both cellular reprogramming and lineage-directed differentiation factors, particularly for the identification and functional characterization of the genetic/epigenetic determinants $[60,61]$.

2.2. Integration-Free Method. Current retroviral or lentiviral reprogramming strategies are utilizing the integration of TFs into host genome, increasing concerns of oncogenicity and mutagenesis $[62,63]$. These viral transgene approaches are unlikely to be suitable for future clinical applications but are still important tools for basic studies. The transduction of exogenous TFs aims to activate the expression of endogenous pluripotent genes as a means of triggering the reprogramming process. This presents a need for an alternative way to accomplish this purpose. To solve this technical limitation of iPSC generation, reprogramming processes could potentially be induced using nonintegrating strategies. Recently, integration-free approaches are being developed as a promising technique for iPSC generation.

2.2.1. DNA Based Approaches. Using replication-defective adenoviral vectors, the first integration-free iPSCs were generated from fibroblasts and liver cells using adenoviruses transiently expressing OSKM [64]. A second group concurrently generated the virus-free iPSCs from mouse MEFs by repeated transfection of two expression plasmids containing OSKM [65]. The integration-free iPSCs were produced by nonintegrating gene delivery strategies, including Sendai virus $[66,67]$, episome $[68,69]$, minicircle vector [70], and polycistronic plasmids [71, 72]. These studies provided safe approaches with extremely low risk of tumorigenicity, although their reprogramming efficiencies were lower when compared to the transgene integration strategy. These inefficient approaches are poor for generation of patient-specific iPSC lines, particularly from their primary biopsies.

In order to eliminate the risk of oncogenicity in the integration protocols, several laboratories have refined the process by using "excisable" methods, such as transposon systems and Cre-loxP systems, to remove the chromosomally integrated genes (Figure 2(c)). Transposons with mobile genetic elements are semiparasitic DNA sequences which can replicate and spread through the host's genome, and thus can be introduced as discrete pieces of DNA using plasmid transfection protocols $[73,74]$. Recently, the novel piggyBac (PB) and Sleeping Beauty (SB) transposon systems have emerged as promising approaches for ex vivo gene therapy [75]. PB transposons are host-factor independent and integrate stably into the target genome, which can be seamlessly removed by re-expression of PB transposase [74]. Therefore, transposons can be modified as a novel and viable vectors for the delivery of reprogramming factors into somatic cells, providing a safer alternative to viral methods [73]. In $\mathrm{PB}$ protocols, a $\mathrm{PB}$ transposon vector containing reprogramming factors is transfected into MEFs and then removed without trace using $\mathrm{PB}$ transposase to generate stable integration- and mutation-free iPSCs with equivalent efficiencies to retroviral transduction [76, 77]. Compared to the PB transposon system, SB transposon demonstrated several advantages, including higher transfer/integration efficiency and safety [78]. SB transposon containing OSKM can be cotransfected with hyperactive SB transposase to generate iPSC lines and then the integrations completely removed by transient transfection of excision SB transposase [79, 80]. The exogenous genes integrated by other methods such as retroviral or lentivial vectors can also be removed using a Cre-loxP system to decrease the risk of potential insertional mutagenesis [81-83]. Interestingly, SB transposons combined with the Cre-loxP system can also be utilized to create integration-free iPSC lines [78]. In this protocol, the OSKM cassette is flanked by compatible loxP recombination sites in a SB transposon vector and then excised using Cre recombinase after iPSC generation (Figure 2(c)). The reprogramming efficiency of these "excisable" methods was reported up to 1$3 \%$. Despite their success in iPSC generation without a genetic footprint, the use of DNA based approaches unfortunately cannot eliminate the possibility of genomic integration of an exogenous sequence [84].

A more attractive approach allowed for iPSC generation using transfection of mRNAs coding for the reprogramming factors into human primary somatic cells [85]. Although this difficult and uneconomical approach is challenging in practical applications, its reprogramming efficiency is higher than that of conventional approaches and the authors have already made technical improvements [86]. The cDNA sequences of OSKM were amplified from individual vectors and then modified and switched into mRNA using an in vitro transcription kit. Finally, the synthesized mRNA can be directly transfected to generate transgene-free iPSCs, typically yielding several hundred colonies.

2.2.2. DNA-Free Methods. The above studies support the theory that transient expression of the exogenous reprogramming factors is sufficient to induce pluripotency in somatic cells. They also do not require genomic integration and can be eliminated after transfection, giving them an independence that is considered an important criterion of high-quality fully reprogrammed iPSCs. Recently, other DNA-free methods with more convenient manipulations are in development to activate the endogenous pluripotent genes for reprogramming such as microRNAs, recombinant protein, and small molecules.

It is first required to understand the molecular changes underlying iPSC derivation for the development of alternative and safer strategies for reprogramming. Gene expression profiling studies in fibroblasts have revealed three phases 
of reprogramming termed initiation, maturation, and stabilization [87]. During the early phase of reprogramming, exogenous OSKMs bind the enhancers and promoters of four different classes of genes. This increases proliferation of reprogrammable cells, changes histone modifications of somatic genes, initiates mesenchymal-to-epithelial transition (MET), and activates DNA repair and RNA processing. OSKMs thus act as a "pioneer" factor for remodeling the epigenome before cells enter their maturation phase. During maturation phase, stochastic activation of pluripotency markers occurs in addition to transient activation of developmental regulators and glycolysis. In the last phase, the cells eventually stabilize into the pluripotent state with silenced exogenous transgenes, remodeled ESC-like cytoskeleton, reset epigenome, and activated core pluripotency circuitry. The early epigenetic priming events in the process may be critical for pluripotency induction [88, 89]. Thus, substitutions for OSKM can achieve the reprogramming of somatic cells by activating the epigenetic remodeling of pluripotency and MET genes.

\subsubsection{Recombinant Protein Delivery. Recombinant protein} delivery represents a straightforward reprogramming strategy. The first protein-induced pluripotent stem cells (piPSCs) generated using these methods were reported by two independent research groups $[90,91]$. Unfortunately, the poor ability of macromolecules such as protein to cross the cellular membrane often hinders their intracellular delivery. Several groups have attempted to design a protein transduction domain to assist transmembrane transport of the four reprogramming factors (OSKM) [92, 93]. After repeated transfer of these recombinant proteins, results of only three iPSC colonies per $5 \times 10^{4}$ treated cells were achieved [90]. This is an efficiency of iPSC generation of about $0.001 \%$ of input cells, which was significantly lower than that of virusbased protocols [91]. Moreover, a single transfer of ESCderived extract proteins into adult somatic cells achieved full reprogramming up to the pluripotent state, avoiding repeated transfer or prolonged exposure to materials [94]. Mechanistically, the cell-permeant Oct 4 and Sox 2 proteins were shown to specifically bind to the promoter of pluripotent gene, modulating the transcriptional machinery while maintaining pluripotency $[95,96]$. Due to the extremely low efficiency and delayed reprogramming, it is essential to develop a robust and efficient protocol to generate recombinant reprogramming proteins modified for high stability and cell permeability.

2.2.4. Small Molecules. In order to improve the efficiency of nonintegrating reprogramming approaches, several screens for chemical compounds have been performed. A number of small molecules have been identified since, that modulate the induction of reprogramming while significantly improving the efficiency and quality of iPSC generation and functionally replacing exogenous OSKM. A single chemical compound is not able to entirely replace the function of a reprogramming factor in current studies but it can work with other modulators. Named on the basis of their reprogramming mechanisms, they can be classified into epigenetic modifiers, signaling pathway modulators, cell senescence alleviators, and metabolism regulators [84].

Epigenetic modifiers are used most commonly in various iPSC generation protocols because the epigenetic changes (e.g., DNA demethylation and histone acetylation) of pluripotency genes are the key feature of reprogramming. Valproic acid (VPA), a histone deacetylase (HDAC) inhibitor, was initially reported to effectively reprogram primary human fibroblasts without introduction of the oncogene cMyc $[97,98]$. The addition of VPA can also improve the reprogramming efficiency of viral OSKM transduction [99, 100] or recombinant protein delivery [90] directly regulating Oct4 promoter activity to ensure the acquirement and maintenance of pluripotency [101]. Moreover, other HDAC inhibitors and combinations of inhibitors were found to significantly improve the overall efficiency of the reprogramming process in the context of TFs including trichostatin A [98], suberoylanilide hydroxamic acid [102] and sodium butyrate $[103,104]$, DNA methyltransferase inhibitors (5azacytidine [98, 105] and RG108 [106-108]), and histone methyltransferase inhibitors (BIX01294 [106, 107, 109]).

In addition to epigenome remodeling, signal transduction pathways mediated by extrinsic factors and intrinsic transcriptional networks cooperate to reprogram somatic cells into iPSCs [87]. Several small molecules have been identified and employed to generate iPSCs by targeting the signaling pathways relevant to reprogramming. For example, CHIR99021 was reported to activate wingless/INT (Wnt) signaling, which is important in the maintaining and the pluripotency and self-renewal of adult stem cells [110] and significantly improved the reprogramming efficiency in MEFs [111, 112]. The inhibition of epithelial phenotype in MET mechanisms significantly enhanced reprogramming of human somatic cells [113-115]. Molecules affecting other signaling pathways can also facilitate iPSC reprogramming, such as cAMP analog and inhibitors of Src family kinases $[116,117]$.

Organismal aging or senescence was identified as another one of the barriers for iPSC reprogramming, resulting in slow kinetics and low efficiency of processes [118, 119]. Telomere shortening in cell senescence led to a dramatic decrease in reprogramming efficiency, which was restored by telomerase reintroduction [120]. Longevity-promoting (antiaging) compounds were also reported to promote somatic cell reprogramming [121]. In one example study, vitamin C, an antioxidant agent, was shown to enhance mouse iPSC generation by alleviating cell senescence [122].

iPSC generation requires energy transition from mitochondrial oxidative phosphorylation to perform glycolytic metabolism $[123,124]$. As a result, several metabolism regulators have been identified to upregulate expression of several key glycolytic genes and facilitate iPSC generation. Reprogramming efficiency was also significantly increased by other small molecules, as summarized in other articles $[84,125,126]$.

Remarkably, after the screening of nearly 10,000 small molecules, seven molecule compounds (VPA, CHIR99021, Tranylcypromine, 616452, FSK, and DZNep) were found, 
reprogramming mouse fibroblasts into iPSCs solely, obtaining dozens of iPSC colonies per 50,000 cells [127]. Although the reprogramming efficiency is lower than that of convention viral approaches, it provides an ideal chemical protocol which is more flexible and convenient than the biological protocols dependent on TFs. The usage of a cocktail of chemical compounds eliminates many drawbacks (e.g., tumorigenesis) of the other integration methods. Importantly, the chemical iPSCs can be easily manufactured under current good manufacture practices (cGMP) conditions, making it an economic, practical, and regulatory matter [128]. The chemical reprogramming approach also provides new insight into the minimal or alternate requirements for pluripotency induction.

2.2.5. MicroRNA Based Methods. In addition to pluripotent TFs, endogenous specific microRNAs (miRs) have been reported to be highly expressed in ESCs, termed ESC-specific miRNAs $[129,130]$. They have been demonstrated to play a critical role in the control of pluripotency-related genes mediating self-renewal, differentiation, and dedifferentiation $[131,132]$. miRs are small evolutionary conserved noncoding RNAs and usually act as endogenous repressors controlling gene posttranscription, either by inducing mRNA degradation or by blocking translation $[133,134]$. Each $\mathrm{miR}$ can target and suppress hundreds of mRNAs, and one gene can be targeted by various miRs, dramatically changing the expression profile and identity of cell phenotype. Several studies have demonstrated that regulation networks are very important in governing cell differentiation, development, and disease $[135,136]$. And as a result, researchers are attempting to revert somatic cells back to an ESC-like state using ectopic introduction of ESC-specific miRs. These in turn can be used to generate viral free iPSCs in the absence of any exogenous reprogramming TFs.

The transfection of miR-302-family, for instance, was reported to reprogram several human cancer cell lines into an ESC-like pluripotent state, with similar gene expression patterns and differentiation functions [137]. Several miRNA mimics have also been found to have similar effects. For instance, miR-291, miR-294, and miR-295 can increase the efficiency of reprogramming by OSK, without the requirement of c-Myc induction, and were identified as the downstream effecters of c-Myc and can substitute for its reprogramming effect [138]. Two independent Cell Stem Cell reports showed that human and mouse somatic cells can be reprogrammed to produce iPSCs by expressing microRNAs, completely eliminating the need for ectopic gene expression [139]. miR-based reprogramming approach was two orders of magnitude more efficient than the conventional OSKM methods [140]. Importantly, miR-200 family was showed as the unique mediators of the endogenous reprogramming factors Oct4/Sox2 [141]. Intriguingly, Sox2 directly regulated endogenous miR-29b expression which was required for OSKM- and OSK-mediated reprogramming [142]. Mechanistically, the ESC-specific miRs (such as miR302 family) enhanced reprogramming of somatic cells by repressing multiple target genes $[143,144]$. A new miRNA family (miR-130/301/721) was reported as an important regulator of iPSC induction by targeting transcription factor [145]. Several microRNAs, including miR-93 and miR-106b, have very similar seed sequence regions greatly enhancing iPSC induction by modulating identical target genes in the initiation stage of reprogramming [146]. Their target genes regulate various complicated cellular processes, including cell cycle, MET, epigenetic regulation, and vesicular transport, which are involved in the mechanisms of cell reprogramming $[143,147]$. These genes could be the barrier of somatic cell reprogramming, which can be alleviated by the addition of miRs. At the last step, the core endogenous pluripotency networks were activated in iPSC colonies, similar to TFmediated reprogramming.

The inhibition of microRNAs enriched in somatic cells may also facilitate the reprogramming procedure. For example, loss of miR-145 impaired differentiation and elevated its direct target genes, including Oct4, Sox2, and Klf4, but its increasing expression inhibited ESC self-renewal, repressed pluripotent genes, and induced lineage-restricted differentiation [148]. Another study showed that depletion of miR-21 and miR-29a enhanced reprogramming efficiency in MEFs by regulating p53 and ERK1/2 pathways [149]. As a p53 target, the miR-34 family can repress expression of pluripotent genes and its genetic ablation promoted iPSC generation without compromising self-renewal or differentiation [150]. Sirtuin1 was also reported to facilitate iPSC generation from mouse MEF through the inhibition of the miR-34a and p53 pathways [151]. A recent study showed that the let-7 family acts as an inhibitory influence on reprogramming through a prodifferentiation pathway (including EGR1) and the inhibition of let7 in human cells promotes reprogramming due to an increasing level of its target LIN-41/TRIM71, which is important for overcoming the let-7 barrier to reprogramming [152]. Thus, the microRNA based strategies, including the increase of ESC-enriched miRs and the decrease of ESC-depleted miRs, contribute to the mechanism studies of cell reprogramming. Furthermore, the miR mimic or inhibitor induction approach needs to be optimized, since the reprogramming efficiencies dependent on various miR families may differ during the course of reprogramming and sequential delivery paradigms.

\section{The Potential Application of Somatic Cell Programming Strategy}

The somatic cell reprogramming and iPSC generation approach have only recently become a popular target for regenerative medicine research, but there has been tremendous enthusiasm in translational studies of iPSCs within every field of medicine. Specific differentiation into the 3 primary germ layers and all the cell types potentially provides many benefits for cell-based therapies, disease modeling, and drug development [153-155].

3.1. Differentiation Potentials for Cell Transplantation Therapy. Various cell delivery approaches have been developed to enhance stem/progenitor cell engraftment, survival, and integration to host tissues after MI and have been performed in multiple clinical trials of cardiac regenerative therapy, as summarized in our review [156]. However, 
the most urgent task is to identify ideal seed cells with the highest differentiation potentials for the repair of injured heart. Most current clinical trial studies on MI are using endogenous stem/progenitor cells, including cardiac progenitor cells (CPCs), bone marrow mononuclear cells (BMMC), endothelial progenitor cells (EPCs), mesenchymal stem cells (MSCs), and skeletal myoblasts (SMBs) due to the safety concerns [157, 158]. Resident CPCs (or cardiac stem cells, CSCs) have demonstrated positive therapeutic effects using cardiac differentiation, while other circulating progenitor cells have had mixed results with limited cardiac potential in clinical trials [159-161]. Unfortunately, the ability of CPCs to acquire a cardiomyogenic phenotype is subject to temporal limitations and display limited potential for self-renewal and differentiation $[154,162]$. The therapeutic benefits of CPCs resulted mainly from release of paracrine factors and the isolation and identification of various populations still needs to be investigated $[158,163]$. These limitations do not apply to ESCs or iPSCs which can be propagated indefinitely. Most laboratories can expand various iPSCs robustly using commercially available products, including feeder and feederfree protocols $[164,165]$. They are also able to generate large numbers of unambiguous cardiomyocytes with defined induction protocols. Although there may be some epigenetic differences between iPSCs and ESCs, they are remarkably similar and their derived cardiomyocytes have a very similar phenotype $[166,167]$. Since the use of ESCs is limited due to ethical considerations, iPSCs are emerging as an ideal potential supply of human cardiomyocytes and offer a viable option for an autologous cell source for cardiac regenerative therapy.

3.1.1. Cardiovascular Differentiations. Patient specific or autologous iPSC-derived cells will play an increasingly important role for replacing lost or damaged tissues [168]. The correction approaches to autologous mutant iPSCs can be employed for repairing single-gene disorders, such as Duchenne muscular dystrophy and antitrypsin deficiency $[169,170]$. Cardiovascular cells derived from iPSCs provide a promising seed cell resource for myocardial tissue engineering and have emerged as a novel therapeutic paradigm for MI treatment.

There are 3 major approaches for differentiation of human iPSCs to cardiomyocytes including embryoid body (EB) [167, $171,172]$, monolayer culture [173], and inductive coculture [174]. These in vitro differentiation approaches were established mainly according to the sequential stages of embryonic cardiac development and modified by various signaling factors, such as bone morphogenetic proteins (BMPs), Wnts, and fibroblast growth factors (FGFs) [175-177]. The timing and relative expression of various growth factor combinations can induce the development of a cardiogenic mesoderm. Multiple complex interactions between these conserved signaling pathways control the initial differentiation, proliferation, and maturation of myocardium [178].

The aptitude of iPSCs for de novo cardiac differentiation has been demonstrated, as well their potential for MI therapy. Despite in vitro protocols recapitulating the cardiomyogenic phenotype after the discovery of iPSCs, the first in vivo study in MI treatment was reported in 2009 [179]. The intramyocardial delivery of iPSC colonies was first demonstrated to rescue postischemic myocardial structure and function, achieving in situ regeneration of cardiac, smooth muscle, and endothelial tissue [179]. Human iPSCs can also be established from dermal fibroblasts of patients with advanced heart failure and differentiated into functional cardiomyocytes and in vivo transplantation studies in the rat heart revealed structural integration with host cardiac tissue [180]. Because of the huge demands from basic research and clinical applications, there is great demand for large numbers of functional cardiovascular cells derived from iPSCs or ESCs. To this end, the iPSC- or ESC-derived contracting EBs which contained high percentages (up to 95\%) of pure functional cardiomyocytes were generated by using an optimal culture protocol [181]. An efficient protocol using glycogen synthase kinase 3 inhibitor and other molecules was also reported to produce a high yield $\left(0.8-1.3\right.$ million cells $\left./ \mathrm{cm}^{2}\right)$ of pure $(80-98 \%)$ functional cardiomyocytes from multiple cell lines without cell sorting or selection $[182,183]$.

The cardiomyocytes derived from iPSC or ESCs have been shown to improve cardiac functions after transplantation, but the functional integration of grafts into injured heart tissue has not been demonstrated. The transplantation of ESC-derived cardiomyocytes in uninjured heart had consistent $1: 1$ host-graft coupling, while the grafts in injured hearts were more heterogeneous and typically included both coupled and uncoupled regions [184]. Thus, the functional integration of implanted cardiomyocytes needs to be improved by optimized culture and induction systems which include morphological integration and electromechanical coupling. Intriguingly, the coculture of MSCs or MEFs was showed to improve electrical integration of iPSC-derived cardiomyocytes with ventricular tissues, indicating that soluble factors were involved in electrical coupling [185].

In addition to cardiomyocytes, other cardiovascular cell lineages, such as endothelial cells (ECs) and smooth muscle cells, play an important role in the functional restoration of MI [186, 187]. After injection into ischemic rat heart, the human iPSC-derived cardiac progenitor cells engrafted, differentiated into cardiomyocytes, endothelium and smooth muscle, and persisted for at least 10 weeks after infarction [188]. Compared to BMMC and HUVECs, the functional ECs generated from ESCs or iPSCs demonstrated better therapeutic efficacy for attenuation of ischemic tissues [189]. The purified CD31 and CD146 positive vascular progenitors from cord blood-derived iPSC were reported to home and engraft into ischemic tissues, with incorporation into damaged vessels [190]. Importantly, the refinement of EC differentiation methods enriched for subtype-specific iPSCECs, including arterial, venous, and lymphatic subtypes, with functional benefits of enhancing neovascularization [191].

It has become clear that cell therapies combined with tissue engineering techniques (such as myocardial cell sheets) can increase stem cell survival and retention, thereby enhancing therapeutic effects [192]. A cardiac tissue sheet reassembled with defined cardiovascular populations (including purified hiPSC-derived cardiomyocytes and 


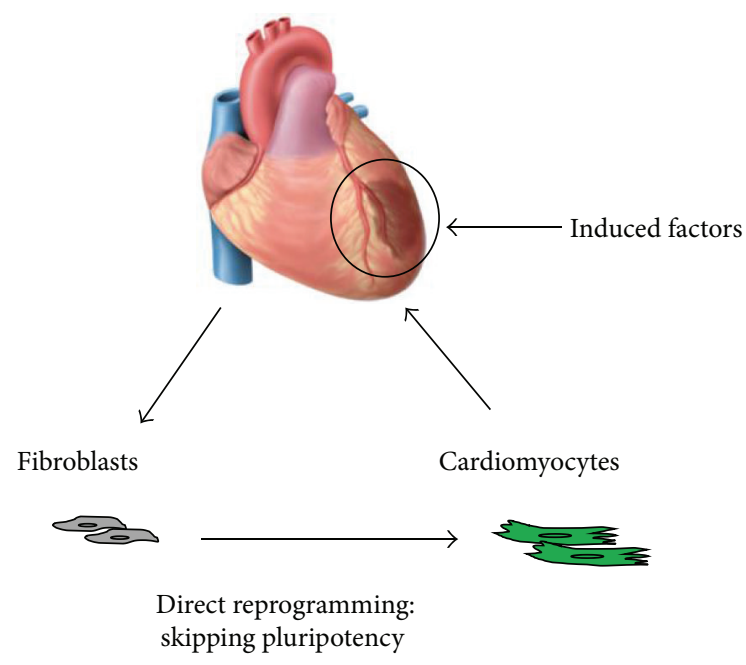

FIGURE 3: The model of direct reprogramming of fibroblasts into cardiomyocytes in infarct heart. The transient overexpression of cardiac specific TFs, GMT, is able to generate cardiac lineagespecific cells directly from somatic cells. This process "skipping pluripotency" does not require transition through a pluripotent intermediate, immensely eliminating the risk of tumorigenicity.

ECs) was implanted in an animal MI model which showed significant and sustained improvement of cardiac function accompanied by neovascularization [193, 194]. In our studies, a tricell omentum patch (seeded with iPSC-derived cardiomyocytes, ECs, and MEFs) was created and implanted into mice resulting in significantly higher cell engraftment accompanied by angiomyogenesis in the infarcted area and improvement in heart function $[195,196]$. The combination of cell sheet and the omentum flap has emerged as a promising iPSC technique for the development of tissue-engineered vascular-rich new myocardium in vivo [197]. Notably, the long-term persistence of transplanted iPSC-derived cardiac cells demonstrated an electrical integration into host tissue with the presence of electrophysiological maturation and improved quality, supporting their potential for myocardial replacement therapy [198].

\subsubsection{Direct Reprogramming for Cardiovascular Regenera-} tion. Transdifferentiation is a new paradigm that has been devised to generate cardiovascular lineage-specific precursor cells directly from somatic cells (Figure 3), by combining transient overexpression of the cardiac specific TFs. At first, the transfections of specific TFs (Gata4, Mef2c, and Tbx5) transdifferentiated mouse postnatal cardiac or skin fibroblasts directly into cardiomyocyte-like cells, but with a very low efficiency [199]. Alternative in vitro methods demonstrated temporal overexpression of OSKM with the addition of signaling molecules that directly reprogrammed mouse fibroblasts into spontaneously contracting patches of cardiomyocytes over a period of 11-12 days, during which no pluripotent intermediates arose [200].

Direct myocardial reprogramming continues to be explored under in vivo circumstances using ischemic heart models. For instance, the injection of GMT retrovirus into mouse infarcted hearts induced infected cells to express cardiac-specific genes [201]. Furthermore, genetic lineage tracing showed that resident nonmyocytes can be reprogrammed into cardiomyocyte-like cells by the retroviral delivery of GMT in mouse infarcted heart [202, 203]. Their induced cardiomyocytes presented binucleate and assembled sarcomeres, as well as cardiomyocyte-like gene expression, and electrical coupling. They also found that the delivery of the proangiogenic and fibroblast-activating peptide thymosin beta4 along with GMT resulted in further improvements of cardiac function. Alternatively, four transcription factors, Gata4, Hand2, Mef2C, and Tbx5, can cooperatively reprogram adult mouse tail-tip and cardiac fibroblasts into cardiac-like myocytes in vitro and their overexpression improved cardiac function and reduced adverse ventricular remodelling following $\mathrm{MI}$ by in vivo direct reprogramming into functional cardiac-like myocytes [204].

However, the GMT overexpression in murine tail-tip fibroblasts and cardiac fibroblasts is an inefficient method to induce direct myocardial reprogramming, and lacks the molecular and electrophysiological phenotypes of mature cardiomyocytes [205]. The authors also found that transplantation of GMT infected cardiac fibroblasts into injured mouse hearts resulted in decreased cell survival with minimal induction of cardiomyocyte genes. Thus, there are significant challenges in the direct reprogramming of fibroblasts into cardiomyocyte-like cells and an increase in the translational potential of this strategy is required.

Interestingly, pretreatment of VEGF to infarcted myocardium was reported to enhance the efficacy of the GMT-mediated reprogramming strategy, improving myocardial function and reducing the extent of myocardial fibrosis [206]. Since the initial GMT approach was not sufficient for cardiac induction in human cardiac fibroblasts, a study screening for additional factors found that the transduction of Mespl and Myocd enhanced the direct reprogramming efficiency [207]. This strategy used a discrete set of factors but had critical epigenetic blocks in the process of in vitro cardiac reprogramming, which were attenuated in their native environment in vivo $[199,202,204]$. This phenomenon suggests the important role of epigenetic mechanisms in reprogramming process. DNA methylation and histone modifications are the major components of epigenetics in the regulation of gene expression [208]. The promoter regions of cardiac specific genes were comparatively demethylated in the induced cardiomyocytes [199]. With regards of the enrichment of histone modifications, trimethylated histone $\mathrm{H} 3$ of lysine 4 (H3K4me3, marks transcriptionally active chromatin) was increased on the promoter regions of cardiac specific genes, while trimethylated histone $\mathrm{H} 3$ of lysine 27 (H3K27me3, marks transcriptionally inactive chromatin) was significantly reduced upon reprogramming [199]. Therefore, the understanding of epigenetic mechanisms which were found to be involved in this process is important for enhancing the conversion efficiency $[209,210]$. The inefficient generation of iPSCs reveals that the major epigenetic barriers in somatic cells cannot be easily overcome $[89,211]$. Thus, it is required to continue the genome-wide epigenetic studies of cardiac 
reprogramming and to develop alternative approaches (such as small molecules) targeting the stable epigenetic events. For example, epigenetically active small molecules were employed to change global histone modifications of human cardiac stromal cells, thereby driving them reprogrammed into functional cardiovascular precursors [212].

"Skipping pluripotency" is an alternative strategy for the production of functional endothelial cells directly induced from somatic cells. This reprogramming approach mediated by epigenetic mechanisms does not require transition through a pluripotent intermediate during the process of transdifferentiation, immensely eliminating the risk of tumorigenicity. This provides a new line of thought for the generation of lineage-specific cell types derived from somatic cells and may facilitate the potential applications of reprogramming in cardiac regenerative therapy. In one study, human fibroblasts were induced to generate partial-iPSC for 4 days by transfecting OSKM into the nuclei and clearly displayed the potential to differentiate into endothelial cells in response to defined media and culture conditions [213]. The human fibroblasts also can be transdifferentiated into functional endothelial cells by the lentiviral transduction of Oct 4 and Klf4, in chemically defined medium with soluble factors such as BMP4, VEGF, and bFGF [214].

Alternatively, based on the potential of miRNAs regulating developmental and reprogramming processes, a combination of miRNAs was identified to induce direct reprogramming of fibroblasts to cardiomyocyte-like cells in vitro and in vivo [215]. The knowledge and the techniques gained from the development of iPSC reprogramming will be especially beneficial in designing new methods of transdifferentiation. The multipotent cardiovascular precursor cells derived from direct reprogramming of human somatic cells can be a versatile cell source for cell-based therapy in MI treatment. The low efficiency of direct reprogramming, however, will need to be improved.

3.2. Disease Modeling and Drug Screening. In addition to their regenerative capacity in cell therapy, iPSC-derived myocardium provides an important in vitro tool for modeling cardiac diseases, allowing us to study the molecular mechanisms involved in cardiac syndromes and test novel specific gene targets for drug discovery (Figure 4) [216, 217]. It is very convenient and feasible to generate iPSCs from somatic cells (such as skin fibroblasts and blood cells) of specific patients. The iPSCs and derivatives (all of adult cell types) containing specific genetic information of a patient can potentially contribute to development of personalized medicine for diagnostic testing and selecting appropriate therapies [218, 219].

3.2.1. Disease Modeling. The application of human iPSCderived cell types can accurately recapitulate relevant human diseases from animal models. Stem cells are available in essentially unlimited quantities and exhibit a more stable phenotype in long-term culture, which is superior to primary cells. The human specific iPSCs also can also be differentiated into any human cell type and early efforts have focused on four main areas: neurons, hepatocytes, cardiomyocytes, and pancreatic beta islet cells, with widely known molecular and biochemical signals driving in vivo differentiation [220].

The first disease-specific iPSC line was generated from an 82-year-old woman diagnosed with a familial form of amyotrophic lateral sclerosis (ALS) and it was successfully differentiated into motor neurons which were destroyed in ALS [221]. Multiple iPSC lines were then generated from patients with a variety of genetic diseases with either Mendelian or complex inheritance, which can induce both normal and pathologic tissue formations in vitro, thereby enabling disease investigation and drug development [222]. The first time that the application of iPSCs modeling the specific pathology seen in a genetically inherited disease occurred when a child suffering from spinal muscular atrophy was used to produce motor neurons that showed selective deficits when compared to those derived from the child's unaffected mother [223].

Applications of iPSCs for modeling diseases in vitro are destined to expand to encompass numerous disease conditions, as discussed in other reviews [216, 217, 224].

In the study of cardiovascular diseases, human iPSCderived cardiomyocytes can serve as a cardiac model to be used for diverse basic studies ranging from cellular electrophysiology to biochemistry [225]. For example, the iPSCs from patients with hypertrophic cardiomyopathy (who have a mutation in the PTPN11 gene) have been derived and in vitro differentiated cardiomyocytes presented a higher degree of sarcomeric organization and preferential localization of NFATC4 in the nucleus, the disease phenotype [226]. The patient-specific iPSCs from members of a family affected by long-QT syndrome type 1 (ventricular tachyarrhythmia due to mutations occur in the KCNQ1 gene), and the patient-derived "ventricular" and "atrial" cells, recapitulated markedly prolonged duration of action potential, the electrophysiological features of the disorder [227]. The development of an iPSC-derived long-QT syndrome type-2 disease model (which is due to the $\mathrm{A} 614 \mathrm{~V}$ missense mutation in the $\mathrm{KCNH} 2$ gene) was also reported to show significant prolongation of the action-potential duration [228]. Moreover, the cardiomyocytes derived from Timothy syndrome patientspecific iPSCs showed irregular contraction, excess $\mathrm{Ca}^{2+}$ influx, prolonged action potentials, irregular electrical activity, and abnormal calcium transients [229]. Finally, iPSCderived myocardium can be used to reproduce the in vitro characteristics of familial hypertrophic cardiomyopathy [230, 231], right ventricular cardiomyopathy [232], and cardiac $\mathrm{Na}^{+}$ channel disease $[233,234]$. These iPSC-derived cell models can provide a physiologically and functionally relevant human cellular context in vitro to reveal the pathogenic mechanism underlying the specific disease phenotype [235].

3.2.2. Drug Screening and Evaluation. In addition to the investigation of the mechanisms of human diseases, iPSCderived cell models also play an important role in the evaluation of the potential therapeutic efficacy of drugs or small molecules. In this regard, access to abundant populations of human cardiomyocytes is of particular interest to the pharmaceutical industry as a tool to develop new cardioactive compounds for correcting cardiac disease phenotypes and for screening the potential cardiotoxicity of new compounds. 


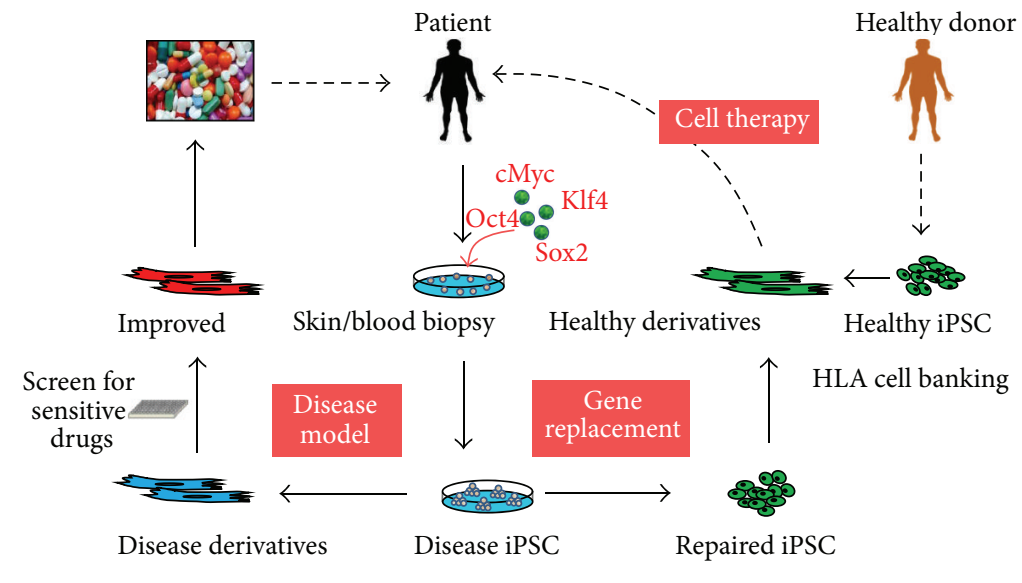

Challenges: low efficiency, tumorigenicity, functional maturation, and immunogenicity

FIGURE 4: The potential applications and challenges of iPSCs in cardiac regenerative medicine. iPSCs are a cell therapy strategy for replacing lost or damaged cardiac tissues. They can be generated from patient specific somatic cells and are capable of generating large numbers of unambiguous cardiomyocytes using defined protocols. The major challenges in the current translational studies are concerns about the specificity of function maturation, low efficiency, immunogenicity, and safety of iPSCs. In addition to their applications in cell therapy, iPSCderived cardiovascular cells provide an important in vitro tool for modeling cardiac diseases and drug screening. Clinical-grade HLA cell banking is one strategy being developed to minimize the risk of immunogenicity of iPSCs.

One such study employed the use of cardiomyocytes differentiated from patients with arrhythmogenic disorders. Patient-specific iPSCs were used as a guide for assessing drug therapeutic effects and tailoring medical treatment for patients [236]. This cardiac-tissue model was used to evaluate the potency of existing and novel pharmacological agents on cardiomyocytes derived from patients with longQT syndrome and the disease phenotype was found to be impacted by the treatment with various $\beta$-adrenergic receptor blockers [227]. Dantrolene, for example, was identified to restore abnormal $\mathrm{Ca}^{2+}$ spark properties and rescued the arrhythmogenic phenotype of an iPSC-derived model of catecholaminergic polymorphic ventricular tachycardia [237].

Finally, iPSC can be used for the identification of novel target genes that play a potential role in the development of therapies for myocardial diseases. When molecular mechanisms of relevant diseases are recapitulated, the identification of gene candidates could be used for target-agnostic drug screening. RNA interference (RNAi) technology has been applied on a genome-wide scale for several biological processes to identify the potential new targets effectively [238]. Since gene therapy techniques are complicated and controversial, conventional chemical compounds are preferable in the discovery of new drugs by targeting the diseased genes. The combination of patient-derived iPSC disease models with RNAi technologies presents a great opportunity to not only identify disease-relevant biological signatures but to also discover novel drug targets [224]. With the expression profiling of healthy and diseased cells, systematic RNAi knockdown of gene candidates can identify potential therapeutic targets, if the specific gene knockdown can correct a disease phenotype. By screening the compound libraries based on the target genes, compounds could be used that mimic the effect of gene knockdown and then be tested for efficacy in the relevant iPSC disease models as new drugs [224].

Adverse reactions and drug toxicity represent major challenges for pharmaceutical industries, contributing to the high cost of drug development. Thus, it is important to develop the predictive human cellular systems for the complementation of current toxicity tests to establish routine screening for toxicity pathways [239]. Given that the human ESC-derived cell types are most susceptible to drug toxicity, the human iPSCs also can be used in the drug toxicity assays offering a great potential for assessing adverse drug effects [240]. Before the establishment of cell-based toxicity assays that accurately reflect mature tissue phenotypes as discussed above, it would be necessary to improve the hiPSC generation and differentiation protocols significantly [239]. Cardiomyocytes differentiated from human iPSC long-QT syndrome models have actually been used to reflect the tendency of drugs to exacerbate cardiac conduction defects, and thus potentially could be used to screen compounds for cardiotoxicity [241]. Disease-specific hiPSC-cardiomyocytes demonstrated increased susceptibility to known cardiotoxic drugs as measured by action potential duration and quantification of drug-induced arrhythmias, which recapitulated drug-induced cardiotoxicity profiles at the single cell level [242]. And they found that use of disease-specific hiPSCderived cardiomyocytes may predict adverse drug reactions more accurately than the standard gene test or healthy controls. Notably, some kinase inhibitors used in cancer therapy have been associated with toxicities to the heart and vasculature and their cardiotoxicity can be predicted by hiPSC-derived preclinical models [243]. Thus, the iPSCs are employed in personalized drug development to characterize the protective effects or optimal safety doses of therapeutic agents. The current screening models have low-to-moderate 
throughput, and high throughput drug screening models need to be developed for practical use in the pharmaceutical industry [244]. This will require the cell types for reproducible disease modeling with adequate quantity, purity, and quality. The bioreactor process development, cell banking, and automation protocols must also be devised [244]. They will prove to be a powerful approach to reduce drug toxicity, to stratify patient response, and to make less failure in the latestage clinical trial.

\section{Challenges and Perspectives of iPSCs}

Although the discovery of iPSCs is encouraging and has brought forward numerous successful studies, it is just beginning to be used in the preclinical phase of human trials and the potential is still emerging $[245,246]$. It will take a long time and great effort to overcome the major challenges of iPSCs present in cardiac regenerative medicine prior to the development of any clinical applications (Figure 4).

4.1. Low Efficiency. Given the successes of iPSC transplantation experiments in animal models, clinical trials will be taking place in the near future $[245,246]$. Most iPSCs in current studies are produced with integrating DNA vectors which may not get silenced efficiently or potentially disrupt endogenous genes after in vivo transplantation and increasing the risk of oncogenicity or mutagenesis. One favorable factor is that iPSCs can be generated by using integration-free approaches, particularly the combination of small molecules or microRNAs. However, the biggest challenge for the transgene-free approaches is increasing efficiency.

Current progress has contributed to an in-depth investigation of pluripotency mechanisms that are part of the processes of ESC or iPSC generation. Pluripotency reporter models such as Oct4 promoter and GFP transgene mouse $[98,127]$, large scale screening in other DNA, small molecule, or microRNA libraries are all contributing to the discovery of novel pluripotent regulators or specifiers with higher induction efficiency. Ongoing improvement and optimization of current culture systems are also beneficial for enhancing reprogramming efficiency and the maintenance of iPSC selfrenewal.

4.2. Safety Issues. One major pitfall is the tendency for iPSCs to form teratomas and current differentiation protocols cannot completely eliminate residual undifferentiated cells. This problem can be improved by morphological selection, label or staining strategies using fluorescence activated cell sorters (FACS), and drug selection approaches [247249]. For instance, after defined differentiation induction of iPSCs, our previous studies used FACS to isolated CD31 positive derived ECs and purified NCX1 positive derived cardiomyocytes by puromycin resistance selection $[195,196]$. NKX2-5 positive cardiomyocytes from iPSCs were purified by FACS and survived upon transplantation into the infarcted mouse heart without formation of teratomas [250]. Stagespecific embryonic antigen (SSEA) positive cardiovascular progenitors were purified using magnetic beads and were capable of generating cardiomyocytes, smooth muscle, and endothelial cells without the development of teratomas [251]. A novel selection system was reported to purify iPSCderived cardiomyocytes using nanoscale probes with FACS and the transplantation improved cardiac function without forming tumors [252]. Remarkably, a nongenetic purified method based on the marked glucose/lactate metabolism characteristic of cardiomyocytes, generated abundant cardiomyocytes of up to $99 \%$ purity that did not form tumors after transplantation [253].

Although the purity of these isolation protocols was reported up to $\sim 99 \%$, it is still difficult to remove the undifferentiated cells and the differentiated noncardiac cells completely to obtain entirely purified derived cardiovascular cells. Even if very few native iPSCs (included differentiated) are left over, the pluripotent residual and unwanted populations can proliferate after implantation in vivo and bring many unpredicted consequences including benign teratoma formation and malignant transformation [254]. "Skipping pluripotency" has emerged as an alternative strategy for production of functional cell types directly reprogrammed from somatic cells, significantly eliminating the risk of tumorigenicity.

It is advantageous for iPSCs or ESCs to be propagated indefinitely in vitro, because current models of cell therapy can require hundreds of millions to billions of cells for each patient [255]. However, prolonged expansion of iPSCs or ESCs has been found to produce genomic abnormalities including chromosomal aneuploidy, translocations, megascale duplications and deletions, and point mutations [256]. The generation of iPSC is analogous to the inner cell mass during embryogenesis, which is accompanied with naturally prevalent chromosome instability [257]. Thus, in response to DNA damage and replicative stress such as ultraviolet exposure, a minority of pluripotent stem cells can still proliferate with deficient DNA damage repair and cell-cycle arrest, leading to point mutations [258]. The accumulation of such stochastic genetic lesions can cause the loss of tumor suppressor genes or gain of proliferation genes, increasing the tumorigenic potential of iPSCs or ESCs during long periods of culture and propagation. These findings highlight the need for stringent enforcement of in vitro expansion conditions and maintenance standards for iPSC lines to ensure the normal chromosomal integrity prior to clinical application.

4.3. Immature Differentiation. Although some laboratories describe successful variable cell differentiation approaches, the conversion of pluripotent cells to terminally differentiated cells (such as cardiomyocytes) is initially inefficient and not readily transferable across various cell lines. It is also very difficult to find the derivatives of many mature cell types. These limitations must be overcome in order to obtain high quality generation of in vitro mature myocardium for basic research and clinical applications. The cardiomyocytes derived from iPSCs or direct reprogramming of somatic cells is immature and lacks the consistent characteristics of 
adult mature ventricular cardiomyocytes, so they are called cardiomyocyte-like cells. These cells are reflective of very early human cardiac development, limiting their utility in the generation of in vitro models of mature myocardium. Immature differentiated cardiomyocytes lack the consistent properties of adult mature ventricular cardiomyocytes such as gene expression profile, morphology, and electrophysiological function $[158,259,260]$. For instance, the majority of hiPSC-derived cardiomyocytes lack the action potential notch characteristic which is central to the disease phenotype of inherited cardiac arrhythmia syndromes [261]. The diversity of various induced cardiomyocyte phenotypes is dependent on their derivation, age, and culture conditions. However, when the immature cardiomyocytes are maintained in culture for a prolonged period, they progressively develop a more mature phenotype without signs of differentiation and acquired functionality of both gene expression and electrophysiology [262].

Scientists continue to refine current protocols and improve cardiac differentiation and maturation of iPSCs, combining optimal devices, culture conditions, materials, and timing [178]. Small molecules and microRNAs were also reported to improve cardiac differentiation and maturation of iPSCs and ESCs $[263,264]$. The treatment of ascorbic acid, a small molecule, was also reported to enhance cardiac differentiation and maturation of iPSCs simply, universally, and efficiently [265]. This was demonstrated by dramatically augmenting yield, better sarcomeric organization, and improved electrophysiological functions. Interestingly, biowires is a platform that combines three-dimensional cell cultivation with electrical stimulation to mature hiPSC-derived cardiac tissue, increasing myofibril ultrastructural organization, elevating conduction velocity, and improving both electrophysiological and $\mathrm{Ca}^{2+}$ handling properties [266]. Cell surface markers (such as Flt1 and Flt4) can be used to identify and isolate the cardiac cardiovascular progenitor population derived from iPSCs, and their transplantation has demonstrated a robust ability for engraftment and differentiation into morphologically and electrophysiologically mature adult cardiomyocytes [267].

4.4. Immunogenicity. Before any clinical applications are feasible, the translational studies of stem/progenitor cell based therapy must be able to ensure that the progenies are stable (no differentiation), functional (therapeutic recovery), and safe (no tumorigenicity). Grafts should not elicit severe immune responses of any sort that could threaten the survival of donor cells after transplantation. The probability of immunogenicity associated with the transplantation of stem/progenitor cells and their derivatives has not been clearly addressed and remains one of the greatest obstacles to clinical applications [268]. Initially, teratomas formed by autologous iPSCs can induce T-cell-dependent immune responses in syngeneic recipients, caused by the abnormal expression of multiple genes [269]. Transplantation of allogenic iPSC-derived cardiomyocytes was observed an acute rejection from receipts, while transplantation of syngeneic
iPSCs and derived cardiomyocytes was also observed progressive immune cell infiltration, as well the in vivo differentiation of syngeneic iPSCs [270]. Although these reports are challenging against such an optimistic view of iPSC studies, many unanswered questions are still left, such as their various derivatives and generation approaches [271]. It is encouraging that immune responses and abnormal gene expression were not observed in various tissues derived from the integration-free iPSC after transplantation [272] and there has been evidence supporting increased $\mathrm{T}$ cell proliferation and immune response in syngeneic iPSC-derived specific cells after transplantation [273]. These conflicting conclusions from the studies may be attributable to the different iPSC lines they used. It also may be attributed with partial reprogramming and genetic instabilities in iPSCs that then elicit immune responses. Alternatively, gene integration in transcriptionally active sites could occasionally cause continuous leakage of transgenes or activation of neighbor genes that may be correlated to aberrant expression of an immunogenic protein [274]. It is necessary to carefully screen the gene expression profiles in each cell type for potential immunogenicity for future clinical applications as well as the karyotype information of each iPSC clone.

The iPSC-based autologous methods can avoid the issues of immunogenicity or immunological rejection, while the allogeneic iPSCs can induce severe immune reactions. Autologous iPSCs generation is often associated with high medical costs and longer hospital duration using the current methods as discussed above. The rapidly effective treatment of some disorders, such as acute MI and spinal cord injury, cannot be achieved within the necessary time frame and it is unrealistic to generate autologous iPSCs from the patient's biopsy during the ongoing surgery. Although the healthy autologous iPSCs can be collected and stored in "private cell banking" and serve as primary sources for future use, it will be problematic to achieve this on a large scale due to relatively inefficient reprogramming techniques and high costs $[275,276]$. Therefore, it is important to take the allogeneic iPSCs into consideration for regenerative medicine and tissue engineering. Yamanaka and other groups are currently developing clinical-grade "public cell banking" of primary and differentiated iPSCs from health and disease donors based on their types of human leukocyte antigen (HLA) [277, 278]. One important purpose of their projects is to clarify the immunological impact of HLA matching for allogeneic iPSC transplantation. According to their estimate, an iPSC bank from the selected homozygous HLA-typed volunteers could cover up to $90 \%$ of their ethnic groups [271, 278]. Based on experience in bone marrow transplantation, matching the three major types of HLA loci (including A, B, and DR) between the recipient and donor is expected to eliminate immune rejection after transplantation. In an HLA-matched but minor antigen mismatched allogeneic transplantation setting, it must be careful to select less immunogenic iPSC clones and differentiated cells, and also to monitor and minimize the risk of immunogenicity by using various strategies. A shortterm immunosuppressive approach is capable of inducing engraftment of transplanted ESCs and iPSCs by blockade of leucocyte co-stimulatory pathways [279]. 


\section{Summary}

Contributions from multiple studies have guided iPSC research from their discovery to theory and methods of generation, as well as future directions in clinical use. These studies indicate that a network of TFs plays a central role in the maintenance of pluripotency and self-renewal of pluripotent stem cells. The reprogramming of somatic cells back into the embryonic state with pluripotency was realized by overexpressing four pluripotent factors. Most laboratories can now expand various iPSCs robustly using commercially available products according to established protocols. There has since been tremendous enthusiasm in studies of iPSCs within almost every field of medicine. However, there are many limitations for retroviral reprogramming approaches. Many nonintegrating strategies are being developed for the reprogramming process, and the chemical reprogramming protocols can be successful with a combination of different compounds, providing new insight into the minimal or alternate requirements for pluripotent TFs. Studies on the mechanisms of pluripotency induction indicate that all the reprogramming factors are interchangeable. This is a very important consideration in that the manipulation and improvement of iPSC generation is feasible and flexible with an ultimate goal of activation of endogenous pluripotent networks. All of these approaches need to be optimized including gene delivery methods, growth conditions, culture timing, and target cell selection in order to increasing the reprogramming efficiency.

Compared to other stem/progenitor cells, iPSCs can be propagated indefinitely and are able to generate large numbers of functional cardiomyocytes with defined induction protocols. However, prolonged expansion and culture should be avoided due to the increasing risk of chromosomal abnormalities. Derived cardiovascular cells are emerging as an ideal potential option for an autologous cell source for cardiac regenerative therapy. Importantly, a reprogramming strategy that "skips pluripotency" has been developed for the production of functional cell types directly induced from somatic cells under defined conditions. It does not require transition through a pluripotent intermediate and virtually eliminates the risk of tumorigenicity by mediating epigenetic mechanisms. This approach of de novo cell generation provides a new direction for the potential applications of cardiac regenerative therapy.

In addition to their applications in cell therapy, iPSCderived cardiovascular cells provide an important in vitro tool for modeling cardiac diseases for defining the molecular mechanisms involved in cardiac syndromes. The contained specific genetic information is essential for personalized medicine. They also play an important role in the potential therapeutic efficacy or cardiotoxicity evaluation of new drugs. The application studies of iPSCs are just at the beginning of use at the preclinical phase and their various challenges still need be overcome before extensive clinical usage can occur. Ultimately iPSCs offer a safe and efficient approach for controlling cell fate toward specific cell types and will have a profound effect on bringing iPSC technology closer to clinical application.

\section{Conflict of Interests}

The author declares that there is no conflict of interests regarding the publication of this paper.

\section{Acknowledgments}

This work was supported by NIH Grants, HL089824, HL107957, and HL110740 (Y. Wang).

\section{References}

[1] K. Thygesen, J. S. Alpert, A. S. Jaffe, M. L. Simoons, B. R. Chaitman, and H. D. White, "Third universal definition of myocardial infarction," Journal of the American College of Cardiology, vol. 60, no. 16, pp. 1581-1598, 2012.

[2] B. Swynghedauw, "Molecular mechanisms of myocardial remodeling," Physiological Reviews, vol. 79, no. 1, pp. 215-262, 1999.

[3] R. A. Pedersen, V. Mascetti, and S. Mendjan, "Synthetic organs for regenerative medicine," Cell Stem Cell, vol. 10, no. 6, pp. 646647, 2012.

[4] G. C. Gurtner, M. J. Callaghan, and M. T. Longaker, "Progress and potential for regenerative medicine," Annual Review of Medicine, vol. 58, pp. 299-312, 2007.

[5] J. A. Thomson, "Embryonic stem cell lines derived from human blastocysts," Science, vol. 282, no. 5391, pp. 1145-1147, 1998.

[6] M. J. Evans and M. H. Kaufman, "Establishment in culture of pluripotential cells from mouse embryos," Nature, vol. 292, no. 5819, pp. 154-156, 1981.

[7] M. Evans, "Discovering pluripotency: 30 years of mouse embryonic stem cells," Nature Reviews Molecular Cell Biology, vol. 12, no. 10 , pp. 680-686, 2011.

[8] H. S. Bernstein, "Cardiac repair and restoration using human embryonic stem cells," Regenerative Medicine, vol. 7, no. 5, pp. 697-712, 2012.

[9] C. W. Siu, J. C. Moore, and R. A. Li, "Human embryonic stem cell-derived cardiomyocytes for heart therapies," Cardiovascular and Hematological Disorders Drug Targets, vol. 7, no. 2, pp. 145-152, 2007.

[10] S. Levenberg, J. S. Golub, M. Amit, J. Itskovitz-Eldor, and R. Langer, "Endothelial cells derived from human embryonic stem cells," Proceedings of the National Academy of Sciences of the United States of America, vol. 99, no. 7, pp. 4391-4396, 2002.

[11] M. Boiani and H. R. Schöler, "Regulatory networks in embryoderived pluripotent stem cells," Nature Reviews Molecular Cell Biology, vol. 6, no. 11, pp. 872-884, 2005.

[12] K.-J. Won, Z. Xu, X. Zhang et al., "Global identification of transcriptional regulators of pluripotency and differentiation in embryonic stem cells," Nucleic Acids Research, vol. 40, no. 17, pp. 8199-8209, 2012.

[13] L. A. Boyer, I. L. Tong, M. F. Cole et al., "Core transcriptional regulatory circuitry in human embryonic stem cells," Cell, vol. 122, no. 6, pp. 947-956, 2005.

[14] I. Aksoy and L. W. Stanton, "Pluripotency-regulating networks provide basis for reprogramming," Current Molecular Medicine, vol. 13, no. 5, pp. 695-706, 2013.

[15] T. S. Tanaka, T. Kunath, W. L. Kimber et al., "Gene expression profiling of embryo-derived stem cells reveals candidate genes associated with pluripotency and lineage specificity," Genome Research, vol. 12, no. 12, pp. 1921-1928, 2002. 
[16] H.-H. Ng and M. A. Surani, "The transcriptional and signalling networks of pluripotency," Nature Cell Biology, vol. 13, no. 5, pp. 490-496, 2011.

[17] X. Chen, H. Xu, P. Yuan et al., "Integration of external signaling pathways with the core transcriptional network in embryonic stem cells," Cell, vol. 133, no. 6, pp. 1106-1117, 2008.

[18] T. J. King and R. Briggs, "Changes in the nuclei of differentiating gastrula cells, as demonstrated by nuclear transplantation," Proceedings of the National Academy of Sciences of the United States of America, vol. 41, no. 5, pp. 321-325, 1955.

[19] R. Briggs and T. J. King, "Transplantation of living nuclei from blastula cells into enucleated frogs' eggs," Proceedings of the National Academy of Sciences of the United States of America, vol. 38, no. 5, pp. 455-463, 1952.

[20] S. Noggle, H.-L. Fung, A. Gore et al., "Human oocytes reprogram somatic cells to a pluripotent state," Nature, vol. 478, no. 7367, pp. 70-75, 2011.

[21] I. Hyun, "Moving human SCNT research forward ethically," Cell Stem Cell, vol. 9, no. 4, pp. 295-297, 2011.

[22] M. Stadtfeld and K. Hochedlinger, "Induced pluripotency: history, mechanisms, and applications," Genes and Development, vol. 24, no. 20, pp. 2239-2263, 2010.

[23] H. Sumer, J. Liu, P. Tat, C. Heffernan, K. L. Jones, and P. J. Verma, "Somatic cell nuclear transfer: pros and cons," Journal of Stem Cells, vol. 4, no. 2, pp. 85-93, 2009.

[24] K. Takahashi, K. Tanabe, M. Ohnuki et al., "Induction of pluripotent stem cells from adult human fibroblasts by defined factors," Cell, vol. 131, no. 5, pp. 861-872, 2007.

[25] K. Takahashi and S. Yamanaka, "Induction of pluripotent stem cells from mouse embryonic and adult fibroblast cultures by defined factors," Cell, vol. 126, no. 4, pp. 663-676, 2006.

[26] J. Yu, M. A. Vodyanik, K. Smuga-Otto et al., "Induced pluripotent stem cell lines derived from human somatic cells," Science, vol. 318, no. 5858, pp. 1917-1920, 2007.

[27] N. Maherali and K. Hochedlinger, "Guidelines and techniques for the generation of induced pluripotent stem cells," Cell Stem Cell, vol. 3, no. 6, pp. 595-605, 2008.

[28] A. Saunders, F. Faiola, and J. Wang, "Concise review: pursuing self-renewal and pluripotency with the stem cell factor Nanog," Stem Cells, vol. 31, no. 7, pp. 1227-1236, 2013.

[29] S. Eminli, A. Foudi, M. Stadtfeld et al., "Differentiation stage determines potential of hematopoietic cells for reprogramming into induced pluripotent stem cells," Nature Genetics, vol. 41, no. 9, pp. 968-976, 2009.

[30] N. Malik and M. S. Rao, "A review of the methods for human iPSC derivation," Methods in Molecular Biology, vol. 997, pp. 2333, 2013.

[31] Y. Xu, X. Wei, M. Wang et al., "Proliferation rate of somatic cells affects reprogramming efficiency," The Journal of Biological Chemistry, vol. 288, no. 14, pp. 9767-9778, 2013.

[32] T. A. Baudino, C. McKay, H. Pendeville-Samain et al., "cMyc is essential for vasculogenesis and angiogenesis during development and tumor progression," Genes and Development, vol. 16, no. 19, pp. 2530-2543, 2002.

[33] C. M. D'Cruz, E. J. Gunther, R. B. Boxer et al., "c-MYC induces mammary tumorigenesis by means of a preferred pathway involving spontaneous Kras2 mutations," Nature Medicine, vol. 7, no. 2, pp. 235-239, 2001.

[34] R. Blelloch, M. Venere, J. Yen, and M. Ramalho-Santos, "Generation of induced pluripotent stem cells in the absence of drug selection," Cell Stem Cell, vol. 1, no. 3, pp. 245-247, 2007.
[35] M. Nakagawa, M. Koyanagi, K. Tanabe et al., "Generation of induced pluripotent stem cells without Myc from mouse and human fibroblasts," Nature Biotechnology, vol. 26, no. 1, pp. 101106, 2008.

[36] O. Habib, G. Habib, H. W. Choi et al., "An improved method for the derivation of high quality iPSCs in the absence of c-Myc," Experimental Cell Research, vol. 319, no. 20, pp. 3190-3200, 2013.

[37] S.-H. Chiou, B.-H. Jiang, Y.-L. Yu et al., "Poly(ADP-ribose) polymerase 1 regulates nuclear reprogramming and promotes iPSC generation without c-Myc," Journal of Experimental Medicine, vol. 210, no. 1, pp. 85-98, 2013.

[38] A. Martinez-Fernandez, T. J. Nelson, Y. Ikeda, and A. Terzic, "cMYC independent nuclear reprogramming favors cardiogenic potential of induced pluripotent stem cells," Journal of Cardiovascular Translational Research, vol. 3, no. 1, pp. 13-23, 2010.

[39] A. Giorgetti, N. Montserrat, I. Rodriguez-Piza, C. Azqueta, A. Veiga, and J. C. Izpisúa Belmonte, "Generation of induced pluripotent stem cells from human cord blood cells with only two factors: Oct4 and Sox2," Nature protocols, vol. 5, no. 4, pp. 811-820, 2010.

[40] N. Montserrat, E. Nivet, I. Sancho-Martinez et al., "Reprogramming of human fibroblasts to pluripotency with lineage specifiers," Cell Stem Cell, vol. 13, no. 3, pp. 341-350, 2013.

[41] J. Shu, C. Wu, Y. Wu et al., "Induction of pluripotency in mouse somatic cells with lineage specifiers," Cell, vol. 153, no. 5, pp. 963-975, 2013.

[42] Y. Gao, J. Chen, K. Li et al., "Replacement of Oct4 by Tet1 during iPSC induction reveals an important role of DNA methylation and hydroxymethylation in reprogramming," Cell Stem Cell, vol. 12, no. 4, pp. 453-469, 2013.

[43] M. Wernig, C. J. Lengner, J. Hanna et al., "A drug-inducible transgenic system for direct reprogramming of multiple somatic cell types," Nature Biotechnology, vol. 26, no. 8, pp. 916-924, 2008.

[44] C. A. Sommer, M. Stadtfeld, G. J. Murphy, K. Hochedlinger, D. N. Kotton, and G. Mostoslavsky, "Induced pluripotent stem cell generation using a single lentiviral stem cell cassette," Stem Cells, vol. 27, no. 3, pp. 543-549, 2009.

[45] C.-W. Chang, Y.-S. Lai, K. M. Pawlik et al., "Polycistronic lentiviral vector for "hit and run" reprogramming of adult skin fibroblasts to induced pluripotent stem cells," Stem Cells, vol. 27, no. 5, pp. 1042-1049, 2009.

[46] R. Sprengel and M. T. Hasan, "Tetracycline-controlled genetic switches," Handbook of experimental pharmacology, vol. 178, pp. 49-72, 2007.

[47] T. Yamaguchi, S. Hamanaka, A. Kamiya et al., "Development of an all-in-one inducible lentiviral vector for gene specific analysis of reprogramming," PLoS ONE, vol. 7, no. 7, Article ID e41007, 2012.

[48] A. Nagy, "Secondary cell reprogramming systems: as years go by," Current Opinion in Genetics and Development, vol. 23, no. 5, pp. 534-539, 2013.

[49] N. Maherali, T. Ahfeldt, A. Rigamonti, J. Utikal, C. Cowan, and K. Hochedlinger, "A high-efficiency system for the generation and study of human induced pluripotent stem cells," Cell Stem Cell, vol. 3, no. 3, pp. 340-345, 2008.

[50] D. Hockemeyer, F. Soldner, E. G. Cook, Q. Gao, M. Mitalipova, and R. Jaenisch, "A drug-inducible system for direct reprogramming of human somatic cells to pluripotency," Cell Stem Cell, vol. 3, no. 3, pp. 346-353, 2008. 
[51] T. Matsui, D. Leung, H. Miyashita et al., "Proviral silencing in embryonic stem cells requires the histone methyltransferase ESET," Nature, vol. 464, no. 7290, pp. 927-931, 2010.

[52] M. Stadtfeld, N. Maherali, D. T. Breault, and K. Hochedlinger, "Defining molecular cornerstones during fibroblast to iPS cell reprogramming in mouse," Cell Stem Cell, vol. 2, no. 3, pp. 230240, 2008.

[53] R. Sridharan, J. Tchieu, M. J. Mason et al., "Role of the murine reprogramming factors in the induction of pluripotency," Cell, vol. 136, no. 2, pp. 364-377, 2009.

[54] J. Ellis, "Silencing and variegation of gammaretrovirus and lentivirus vectors," Human Gene Therapy, vol. 16, no. 11, pp. 1241-1246, 2005.

[55] T. Brambrink, R. Foreman, G. G. Welstead et al., "Sequential expression of pluripotency markers during direct reprogramming of mouse somatic cells," Cell Stem Cell, vol. 2, no. 2, pp. 151-159, 2008.

[56] T. P. Zwaka, "Reduce, reuse, reprogram," Nature Methods, vol. 7, no. 1, pp. 39-40, 2010.

[57] S. Markoulaki, J. Hanna, C. Beard et al., "Transgenic mice with defined combinations of drug-inducible reprogramming factors," Nature Biotechnology, vol. 27, no. 2, pp. 169-171, 2009.

[58] B. W. Carey, S. Markoulaki, C. Beard, J. Hanna, and R. Jaenisch, "Single-gene transgenic mouse strains for reprogramming adult somatic cells," Nature Methods, vol. 7, no. 1, pp. 56-59, 2010.

[59] M. Stadtfeld, N. Maherali, M. Borkent, and K. Hochedlinger, "A reprogrammable mouse strain from gene-targeted embryonic stem cells," Nature Methods, vol. 7, no. 1, pp. 53-55, 2010.

[60] M. Abad, L. Mosteiro, C. Pantoja et al., "Reprogramming in vivo produces teratomas and iPS cells with totipotency features," Nature, vol. 502, no. 7471, pp. 340-345, 2013.

[61] A. Golipour, L. David, Y. Liu et al., "A late transition in somatic cell reprogramming requires regulators distinct from the pluripotency network," Cell Stem Cell, vol. 11, no. 6, pp. 769782, 2012.

[62] A. S. Lee, C. Tang, M. S. Rao, I. L. Weissman, and J. C. Wu, "Tumorigenicity as a clinical hurdle for pluripotent stem cell therapies," Nature Medicine, vol. 19, no. 8, pp. 998-1004, 2013.

[63] S. G. Hong, C. E. Dunbar, and T. Winkler, "Assessing the risks of genotoxicity in the therapeutic development of induced pluripotent stem cells," Molecular Therapy, vol. 21, no. 2, pp. 272-281, 2013.

[64] M. Stadtfeld, M. Nagaya, J. Utikal, G. Weir, and K. Hochedlinger, "Induced pluripotent stem cells generated without viral integration," Science, vol. 322, no. 5903, pp. 945-949, 2008.

[65] K. Okita, M. Nakagawa, H. Hyenjong, T. Ichisaka, and S. Yamanaka, "Generation of mouse induced pluripotent stem cells without viral vectors," Science, vol. 322, no. 5903, pp. 949953, 2008.

[66] N. Fusaki, H. Ban, A. Nishiyama, K. Saeki, and M. Hasegawa, "Efficient induction of transgene-free human pluripotent stem cells using a vector based on Sendai virus, an RNA virus that does not integrate into the host genome," Proceedings of the Japan Academy B: Physical and Biological Sciences, vol. 85, no. 8, pp. 348-362, 2009.

[67] T. Seki, S. Yuasa, and K. Fukuda, "Generation of induced pluripotent stem cells from a small amount of human peripheral blood using a combination of activated T cells and Sendai virus," Nature Protocols, vol. 7, no. 4, pp. 718-728, 2012.

[68] Y. Junying, H. Kejin, S.-O. Kim et al., "Human induced pluripotent stem cells free of vector and transgene sequences," Science, vol. 324 , no. 5928, pp. 797-801, 2009.
[69] K. Hu and I. Slukvin, "Generation of transgene-free iPSC lines from human normal and neoplastic blood cells using episomal vectors," Methods in Molecular Biology, vol. 997, pp. 163-176, 2013.

[70] F. Jia, K. D. Wilson, N. Sun et al., "A nonviral minicircle vector for deriving human iPS cells," Nature Methods, vol. 7, no. 3, pp. 197-199, 2010.

[71] B. W. Carey, S. Markoulaki, J. Hanna et al., "Reprogramming of murine and human somatic cells using a single polycistronic vector," Proceedings of the National Academy of Sciences of the United States of America, vol. 106, no. 1, pp. 157-162, 2009.

[72] X. Qu, T. Liu, K. Song, X. Li, and D. Ge, "Induced pluripotent stem cells generated from human adipose-derived stem cells using a non-viral polycistronic plasmid in feeder-free conditions," PLoS ONE, vol. 7, no. 10, Article ID e48161, 2012.

[73] K. Woltjen, R. Hämäläinen, M. Kibschull, M. Mileikovsky, and A. Nagy, "Transgene-free production of pluripotent stem cells using piggyBac transposons," Methods in Molecular Biology, vol. 767, pp. 87-103, 2011.

[74] Z. Ivics, M. A. Li, L. Mátés et al., "Transposon-mediated genome manipulation in vertebrates," Nature Methods, vol. 6, no. 6, pp. 415-422, 2009.

[75] M. Di Matteo, E. Belay, M. K. Chuah, and T. Vandendriessche, "Recent developments in transposon-mediated gene therapy," Expert Opinion on Biological Therapy, vol. 12, no. 7, pp. 841-858, 2012.

[76] K. Yusa, R. Rad, J. Takeda, and A. Bradley, "Generation of transgene-free induced pluripotent mouse stem cells by the piggyBac transposon," Nature Methods, vol. 6, no. 5, pp. 363$369,2009$.

[77] K. Woltjen, I. P. Michael, P. Mohseni et al., "PiggyBac transposition reprograms fibroblasts to induced pluripotent stem cells," Nature, vol. 458, no. 7239, pp. 766-770, 2009.

[78] I. Grabundzija, J. Wang, A. Sebe et al., "Sleeping Beauty transposon-based system for cellular reprogramming and targeted gene insertion in induced pluripotent stem cells," Nucleic Acids Research, vol. 41, no. 3, pp. 1829-1847, 2013.

[79] R. P. Davis, C. Nemes, E. Varga et al., "Generation of induced pluripotent stem cells from human foetal fibroblasts using the Sleeping Beauty transposon gene delivery system," Differentiation, vol. 86, no. 1-2, pp. 30-37, 2013.

[80] S. Muenthaisong, O. Ujhelly, Z. Polgar et al., "Generation of mouse induced pluripotent stem cells from different genetic backgrounds using Sleeping beauty transposon mediated gene transfer," Experimental Cell Research, vol. 318, no. 19, pp. 24822489, 2012.

[81] E. P. Papapetrou and M. Sadelain, "Generation of transgene-free human induced pluripotent stem cells with an excisable single polycistronic vector," Nature Protocols, vol. 6, no. 9, pp. 12511273, 2011.

[82] K. Kaji, K. Norrby, A. Paca, M. Mileikovsky, P. Mohseni, and K. Woltjen, "Virus-free induction of pluripotency and subsequent excision of reprogramming factors," Nature, vol. 458, no. 7239, pp. 771-775, 2009.

[83] S. Chakraborty, N. Christoforou, A. Fattahi, R. W. Herzog, and K. W. Leong, "A robust strategy for negative selection of CreloxP recombination-based excision of transgenes in induced pluripotent stem cells," PLoS ONE, vol. 8, no. 5, Article ID e64342, 2013.

[84] T. Ma, M. Xie, T. Laurent, and S. Ding, "Progress in the reprogramming of somatic cells," Circulation Research, vol. 112, no. 3, pp. 562-574, 2013. 
[85] L. Warren, P. D. Manos, T. Ahfeldt et al., "Highly efficient reprogramming to pluripotency and directed differentiation of human cells with synthetic modified mRNA," Cell Stem Cell, vol. 7, no. 5, pp. 618-630, 2010.

[86] P. K. Mandal and D. J. Rossi, "Reprogramming human fibroblasts to pluripotency using modified mRNA," Nature Protocols, vol. 8, no. 3, pp. 568-582, 2013.

[87] Y. Buganim, D. A. Faddah, and R. Jaenisch, "Mechanisms and models of somatic cell reprogramming," Nature Reviews Genetics, vol. 14, no. 6, pp. 427-439, 2013.

[88] B. Papp and K. Plath, "Epigenetics of reprogramming to induced pluripotency," Cell, vol. 152, no. 6, pp. 1324-1343, 2013.

[89] K. Plath and W. E. Lowry, "Progress in understanding reprogramming to the induced pluripotent state," Nature Reviews Genetics, vol. 12, no. 4, pp. 253-265, 2011.

[90] H. Zhou, S. Wu, J. Y. Joo et al., "Generation of induced pluripotent stem cells using recombinant proteins," Cell Stem Cell, vol. 4, no. 5, pp. 381-384, 2009.

[91] D. Kim, C.-H. Kim, J.-I. Moon et al., "Generation of human induced pluripotent stem cells by direct delivery of reprogramming proteins," Cell Stem Cell, vol. 4, no. 6, pp. 472-476, 2009.

[92] A. El-Sayed, S. Futaki, and H. Harashima, "Delivery of macromolecules using arginine-rich cell-penetrating peptides: ways to overcome endosomal entrapment," AAPS Journal, vol. 11, no. 1, pp. 13-22, 2009.

[93] A. Ziegler, P. Nervi, M. Dürrenberger, and J. Seelig, "The cationic cell-penetrating peptide CPPTAT derived from the HIV-1 protein TAT is rapidly transported into living fibroblasts: optical, biophysical, and metabolic evidence," Biochemistry, vol. 44, no. 1, pp. 138-148, 2005.

[94] H.-J. Cho, C.-S. Lee, Y.-W. Kwon et al., "Induction of pluripotent stem cells from adult somatic cells by protein-based reprogramming without genetic manipulation," Blood, vol. 116, no. 3, pp. 386-395, 2010.

[95] M. Thier, B. Münst, S. Mielke, and F. Edenhofer, "Cellular reprogramming employing recombinant Sox2 protein," Stem Cells International, vol. 2012, Article ID 549846, 10 pages, 2012.

[96] M. Bosnali and F. Edenhofer, "Generation of transducible versions of transcription factors Oct4 and Sox2," Biological Chemistry, vol. 389, no. 7, pp. 851-861, 2008.

[97] D. Huangfu, K. Osafune, R. Maehr et al., "Induction of pluripotent stem cells from primary human fibroblasts with only Oct4 and Sox2," Nature Biotechnology, vol. 26, no. 11, pp. 1269-1275, 2008.

[98] D. Huangfu, R. Maehr, W. Guo et al., "Induction of pluripotent stem cells by defined factors is greatly improved by smallmolecule compounds," Nature Biotechnology, vol. 26, no. 7, pp. 795-797, 2008.

[99] Y. Yoshida, K. Takahashi, K. Okita, T. Ichisaka, and S. Yamanaka, "Hypoxia enhances the generation of induced pluripotent stem cells," Cell Stem Cell, vol. 5, no. 3, pp. 237-241, 2009.

[100] A. Grace, M. McMillan, S. Schmoelzl, and G. Hinch, "187 increased efficiency of deriving bovine stem cell-like colonies using valproic Acid and small-molecule cocktails," Reproduction, Fertility and Development, vol. 26, no. 1, p. 208, 2013.

[101] H. F. Teng, Y.-L. Kuo, M. R. Loo et al., "Valproic acid enhances Oct4 promoter activity in myogenic cells," Journal of Cellular Biochemistry, vol. 110, no. 4, pp. 995-1004, 2010.

[102] G. N. Pandian, K.-I. Shinohara, A. Ohtsuki et al., "Synthetic small molecules for epigenetic activation of pluripotency genes in mouse embryonic fibroblasts," ChemBioChem, vol. 12, no. 18, pp. 2822-2828, 2011.
[103] Z. Zhang and W.-S. Wu, "Sodium butyrate promotes generation of human induced pluripotent stem cells through induction of the miR302/367 cluster," Stem Cells and Development, vol. 22, no. 16, pp. 2268-2277, 2013.

[104] P. Mali, B.-K. Chou, J. Yen et al., "Butyrate greatly enhances derivation of human induced pluripotent stem cells by promoting epigenetic remodeling and the expression of pluripotencyassociated genes," Stem Cells, vol. 28, no. 4, pp. 713-720, 2010.

[105] T. S. Mikkelsen, J. Hanna, X. Zhang et al., "Dissecting direct reprogramming through integrative genomic analysis," Nature, vol. 454, no. 7200, pp. 49-55, 2008.

[106] Y. Shi, J. T. Do, C. Desponts, H. S. Hahm, H. R. Schöler, and S. Ding, "A combined chemical and genetic approach for the generation of induced pluripotent stem cells," Cell Stem Cell, vol. 3, no. 1, p. 119, 2008.

[107] Y. Shi, C. Desponts, J. T. Do, H. S. Hahm, H. R. Schöler, and S. Ding, "Induction of pluripotent stem cells from mouse embryonic fibroblasts by Oct 4 and Klf4 with small-molecule compounds," Cell Stem Cell, vol. 3, no. 5, pp. 568-574, 2008.

[108] Z. Pasha, H. K. Haider, and M. Ashraf, "Efficient non-viral reprogramming of myoblasts to stemness with a single small molecule to generate cardiac progenitor cells," PLOS ONE, vol. 6, no. 8, Article ID e23667, 2011.

[109] J. R. Plews, J. Li, M. Jones et al., "Activation of pluripotency genes in human fibroblast cells by a novel mRNA based approach," PLoS ONE, vol. 5, no. 12, Article ID e14397, 2010.

[110] H. Niwa, "Wnt: what's Needed to maintain pluripotency?" Nature Cell Biology, vol. 13, no. 9, pp. 1024-1026, 2011.

[111] W. Li, H. Zhou, R. Abujarour et al., "Generation of humaninduced pluripotent stem cells in the absence of exogenous Sox2," Stem Cells, vol. 27, no. 12, pp. 2992-3000, 2009.

[112] S. Petkov and H. Niemann, "189 small molecule inhibitors pd0325901 and chir99021 cause reduced expression of pluripotency genes in putative porcine induced pluripotent stem cells," Reproduction, Fertility and Development, vol. 26, no. 1, p. 209, 2013.

[113] T. Lin, R. Ambasudhan, X. Yuan et al., "A chemical platform for improved induction of human iPSCs," Nature Methods, vol. 6, no. 11, pp. 805-808, 2009.

[114] T. Chen, D. Yuan, B. Wei et al., "E-cadherin-mediated cell-cell contact is critical for induced pluripotent stem cell generation," Stem Cells, vol. 28, no. 8, pp. 1315-1325, 2010.

[115] X. Yuan, H. Wan, X. Zhao, S. Zhu, Q. Zhou, and S. Ding, "Brief report: combined chemical treatment enables Oct4-induced reprogramming from mouse embryonic fibroblasts," Stem Cells, vol. 29, no. 3, pp. 549-553, 2011.

[116] Y. Wang and J. Adjaye, "A cyclic AMP analog, 8-Br-cAMP, enhances the induction of pluripotency in human fibroblast cells," Stem Cell Reviews and Reports, vol. 7, no. 2, pp. 331-341, 2011.

[117] J. Staerk, C. A. Lyssiotis, L. A. Medeiro et al., "Pan-src family kinase inhibitors replace Sox 2 during the direct reprogramming of somatic cells," Angewandte Chemie, vol. 50, no. 25, pp. 57345736, 2011.

[118] A. Banito, S. T. Rashid, J. C. Acosta et al., "Senescence impairs successful reprogramming to pluripotent stem cells," Genes and Development, vol. 23, no. 18, pp. 2134-2139, 2009.

[119] P. Phanthong, H. Raveh-Amit, T. Li, Y. Kitiyanant, and A. Dinnyes, "Is aging a barrier to reprogramming? Lessons from induced pluripotent stem cells," Biogerontology, vol. 14, no. 6, pp. 591-602, 2013. 
[120] R. M. Marion, K. Strati, H. Li et al., "Telomeres acquire embryonic stem cell characteristics in induced pluripotent stem cells," Cell Stem Cell, vol. 4, no. 2, pp. 141-154, 2009.

[121] T. Chen, L. Shen, J. Yu et al., "Rapamycin and other longevitypromoting compounds enhance the generation of mouse induced pluripotent stem cells," Aging Cell, vol. 10, no. 5, pp. 908-911, 2011.

[122] M. A. Esteban, T. Wang, B. Qin et al., "Vitamin C enhances the generation of mouse and human induced pluripotent stem cells," Cell Stem Cell, vol. 6, no. 1, pp. 71-79, 2010.

[123] X. Xu, S. Duan, F. Yi, A. Ocampo, G. H. Liu, and B. J. Izpisua, "Mitochondrial regulation in pluripotent stem cells," Cell Metabolism, vol. 18, no. 3, pp. 325-332, 2013.

[124] C. D. Folmes, T. J. Nelson, and A. Terzic, "Energy metabolism in nuclear reprogramming," Biomarkers in Medicine, vol. 5, no. 6, pp. 715-729, 2011.

[125] S. Zhu, W. Wei, and S. Ding, "Chemical strategies for stem cell biology and regenerative medicine," Annual Review of Biomedical Engineering, vol. 13, pp. 73-90, 2011.

[126] J.-B. Su, D.-Q. Pei, and B.-M. Qin, "Roles of small molecules in somatic cell reprogramming," Acta Pharmacologica Sinica, vol. 34, no. 6, pp. 719-724, 2013.

[127] P. Hou, Y. Li, X. Zhang et al., "Pluripotent stem cells induced from mouse somatic cells by small-molecule compounds," Science, vol. 341, no. 6146, pp. 651-654, 2013.

[128] B. K. Chou and L. Cheng, "And then there were none: no need for pluripotency factors to induce reprogramming," Cell Stem Cell, vol. 13, no. 3, pp. 261-262, 2013.

[129] M.-R. Suh, Y. Lee, J. Y. Kim et al., "Human embryonic stem cells express a unique set of microRNAs," Developmental Biology, vol. 270, no. 2, pp. 488-498, 2004.

[130] H. B. Houbaviy, M. F. Murray, and P. A. Sharp, "Embryonic stem cell-specific microRNAs," Developmental Cell, vol. 5, no. 2, pp. 351-358, 2003.

[131] R. L. Judson, J. E. Babiarz, M. Venere, and R. Blelloch, "Embryonic stem cell-specific microRNAs promote induced pluripotency," Nature Biotechnology, vol. 27, no. 5, pp. 459-461, 2009.

[132] C. Melton, R. L. Judson, and R. Blelloch, "Opposing microRNA families regulate self-renewal in mouse embryonic stem cells," Nature, vol. 463, no. 7281, pp. 621-626, 2010.

[133] M. Lagos-Quintana, R. Rauhut, W. Lendeckel, and T. Tuschl, "Identification of novel genes coding for small expressed RNAs," Science, vol. 294, no. 5543, pp. 853-858, 2001.

[134] E. Huntzinger and E. Izaurralde, "Gene silencing by microRNAs: contributions of translational repression and mRNA decay," Nature Reviews Genetics, vol. 12, no. 2, pp. 99-110, 2011.

[135] J. M. Friedman and P. A. Jones, "MicroRNAs: critical mediators of differentiation, development and disease," Swiss Medical Weekly, vol. 139, no. 33-34, pp. 466-472, 2009.

[136] T. Thum, D. Catalucci, and J. Bauersachs, "MicroRNAs: novel regulators in cardiac development and disease," Cardiovascular Research, vol. 79, no. 4, pp. 562-570, 2008.

[137] S.-L. Lin, D. C. Chang, S. Chang-Lin et al., "Mir-302 reprograms human skin cancer cells into a pluripotent ES-cell-like state," RNA, vol. 14, no. 10, pp. 2115-2124, 2008.

[138] R. L. Judson, J. E. Babiarz, M. Venere, and R. Blelloch, "Embryonic stem cell-specific microRNAs promote induced pluripotency," Nature Biotechnology, vol. 27, no. 5, pp. 459-461, 2009.
[139] R. Sridharan and K. Plath, "Small RNAs loom large during reprogramming," Cell Stem Cell, vol. 8, no. 6, pp. 599-601, 2011.

[140] F. Anokye-Danso, C. M. Trivedi, D. Juhr et al., "Highly efficient miRNA-mediated reprogramming of mouse and human somatic cells to pluripotency," Cell Stem Cell, vol. 8, no. 4, pp. 376-388, 2011.

[141] G. Wang, X. Guo, W. Hong et al., "Critical regulation of miR200/ZEB2 pathway in Oct4/Sox2-induced mesenchymal-toepithelial transition and induced pluripotent stem cell generation," Proceedings of the National Academy of Sciences of the United States of America, vol. 110, no. 8, pp. 2858-2863, 2013.

[142] X. Guo, Q. Liu, G. Wang et al., "MicroRNA-29b is a novel mediator of Sox 2 function in the regulation of somatic cell reprogramming," Cell Research, vol. 23, no. 1, pp. 142-156, 2013.

[143] D. Subramanyam, S. Lamouille, R. L. Judson et al., "Multiple targets of miR-302 and miR-372 promote reprogramming of human fibroblasts to induced pluripotent stem cells," Nature Biotechnology, vol. 29, no. 5, pp. 443-448, 2011.

[144] S.-L. Lin, D. C. Chang, C.-H. Lin, S.-Y. Ying, D. Leu, and D. T. S. Wu, "Regulation of somatic cell reprogramming through inducible mir-302 expression," Nucleic Acids Research, vol. 39, no. 3, pp. 1054-1065, 2011.

[145] N. Pfaff, J. Fiedler, A. Holzmann et al., "MiRNA screening reveals a new miRNA family stimulating iPS cell generation via regulation of Meox2," EMBO Reports, vol. 12, no. 11, pp. 11531159, 2011.

[146] Z. Li, C.-S. Yang, K. Nakashima, and T. M. Rana, "Small RNAmediated regulation of iPS cell generation," EMBO Journal, vol. 30, no. 5, pp. 823-834, 2011.

[147] C.-H. Kuo and S.-Y. Ying, "MicroRNA-mediated somatic cell reprogramming," Journal of Cellular Biochemistry, vol. 114, no. 2, pp. 275-281, 2013.

[148] N. Xu, T. Papagiannakopoulos, G. Pan, J. A. Thomson, and K. S. Kosik, "MicroRNA-145 regulates OCT4, SOX2, and KLF4 and represses pluripotency in human embryonic stem cells," Cell, vol. 137, no. 4, pp. 647-658, 2009.

[149] C.-S. Yang, Z. Li, and T. M. Rana, "microRNAs modulate iPS cell generation," RNA, vol. 17, no. 8, pp. 1451-1460, 2011.

[150] Y. J. Choi, C.-P. Lin, J. J. Ho et al., "MiR-34 miRNAs provide a barrier for somatic cell reprogramming," Nature Cell Biology, vol. 13, no. 11, pp. 1353-1360, 2011.

[151] Y. L. Lee, Q. Peng, S. W. Fong et al., "Sirtuin 1 facilitates generation of induced pluripotent stem cells from mouse embryonic fibroblasts through the miR-34a and p53 pathways," PLoS ONE, vol. 7, no. 9, Article ID e45633, 2012.

[152] K. A. Worringer, T. A. Rand, Y. Hayashi et al., "The let-7/LIN-41 pathway regulates reprogramming to human induced pluripotent stem cells by controlling expression of prodifferentiation genes," Cell Stem Cell, vol. 14, no. 1, pp. 40-52, 2014.

[153] K. Takahashi and S. Yamanaka, "Induced pluripotent stem cells in medicine and biology," Development, vol. 140, no. 12, pp. 2457-2461, 2013.

[154] O. Iglesias-García, B. Pelacho, and F. Prósper, "Induced pluripotent stem cells as a new strategy for cardiac regeneration and disease modeling," Journal of Molecular and Cellular Cardiology, vol. 62, pp. 43-50, 2013.

[155] H. Okano, M. Nakamura, K. Yoshida et al., "Steps toward safe cell therapy using induced pluripotent stem cells," Circulation Research, vol. 112, no. 3, pp. 523-533, 2013.

[156] J. Liang and Y. Wang, "Stem/progenitor cell based therapies for repair of myocardial infarction: current developments in 
methods of cell delivery," Surgery: Current Research, vol. 3, no. 2, p. 131, 2013.

[157] L.-C. Hsiao, C. Carr, K.-C. Chang, S.-Z. Lin, and K. Clarke, "Stem cell-based therapy for ischemic heart disease," Cell Transplantation, vol. 22, no. 4, pp. 663-675, 2013.

[158] M. A. Laflamme and C. E. Murry, "Heart regeneration," Nature, vol. 473, no. 7347, pp. 326-335, 2011.

[159] E. C. Perin, J. T. Willerson, C. J. Pepine et al., "Effect of transendocardial delivery of autologous bone marrow mononuclear cells on functional capacity, left ventricular function, and perfusion in chronic heart failure: the FOCUS-CCTRN trial," Journal of the American Medical Association, vol. 307, no. 16, pp. 1717-1726, 2012.

[160] A. R. Chugh, G. M. Beache, J. H. Loughran et al., "Administration of cardiac stem cells in patients with ischemic cardiomyopathy: the SCIPIO trial: surgical aspects and interim analysis of myocardial function and viability by magnetic resonance," Circulation, vol. 126, no. 11, pp. S54-S64, 2012.

[161] A. Leri and P. Anversa, "Bone-marrow-derived cells and heart failure-the debate goes on," Nature Reviews Cardiology, vol. 10, no. 7, pp. 372-373, 2013.

[162] M.-M. Zaruba, M. Soonpaa, S. Reuter, and L. J. Field, "Cardiomyogenic potential of C-kit ${ }^{+}$-expressing cells derived from neonatal and adult mouse hearts," Circulation, vol. 121, no. 18, pp. 1992-2000, 2010.

[163] I. Chimenti, R. R. Smith, T.-S. Li et al., "Relative roles of direct regeneration versus paracrine effects of human cardiospherederived cells transplanted into infarcted mice," Circulation Research, vol. 106, no. 5, pp. 971-980, 2010.

[164] J. Beers, D. R. Gulbranson, N. George et al., "Passaging and colony expansion of human pluripotent stem cells by enzymefree dissociation in chemically defined culture conditions," Nature Protocols, vol. 7, no. 11, pp. 2029-2040, 2012.

[165] G. Chen, D. R. Gulbranson, Z. Hou et al., "Chemically defined conditions for human iPSC derivation and culture," Nature Methods, vol. 8, no. 5, pp. 424-429, 2011.

[166] S. Yamanaka, "Induced pluripotent stem cells: past, present, and future," Cell Stem Cell, vol. 10, no. 6, pp. 678-684, 2012.

[167] J. Zhang, G. F. Wilson, A. G. Soerens et al., "Functional cardiomyocytes derived from human induced pluripotent stem cells," Circulation Research, vol. 104, no. 4, pp. e30-e41, 2009.

[168] S. Yamanaka, "Patient-Specific pluripotent stem cells become even more accessible," Cell Stem Cell, vol. 7, no. 1, pp. 1-2, 2010.

[169] K. Yusa, S. T. Rashid, H. Strick-Marchand et al., "Targeted gene correction of $\alpha 1$-antitrypsin deficiency in induced pluripotent stem cells," Nature, vol. 478, no. 7369, pp. 391-394, 2011.

[170] A. Filareto, S. Parker, R. Darabi et al., "An ex vivo gene therapy approach to treat muscular dystrophy using inducible pluripotent stem cells," Nature Communications, vol. 4, article 1549, 2013.

[171] C. Mauritz, K. Schwanke, M. Reppel et al., "Generation of functional murine cardiac myocytes from induced pluripotent stem cells," Circulation, vol. 118, no. 5, pp. 507-517, 2008.

[172] K. Schenke-Layland, K. E. Rhodes, E. Angelis et al., "Reprogrammed mouse fibroblasts differentiate into cells of the cardiovascular and hematopoietic lineages," Stem Cells, vol. 26, no. 6, pp. 1537-1546, 2008.

[173] J. Zhang, M. Klos, G. F. Wilson et al., "Extracellular matrix promotes highly efficient cardiac differentiation of human pluripotent stem cells: the matrix sandwich method," Circulation Research, vol. 111, no. 9, pp. 1125-1136, 2012.
[174] G. Narazaki, H. Uosaki, M. Teranishi et al., "Directed and systematic differentiation of cardiovascular cells from mouse induced pluripotent stem cells," Circulation, vol. 118, no. 5, pp. 498-506, 2008.

[175] E. N. Olson, "Gene regulatory networks in the evolution and development of the heart," Science, vol. 313, no. 5795, pp. 19221927, 2006.

[176] E. N. Olson and M. D. Schneider, "Sizing up the heart: development redux in disease," Genes and Development, vol. 17, no. 16, pp. 1937-1956, 2003.

[177] S. Martin-Puig, Z. Wang, and K. R. Chien, "Lives of a heart cell: tracing the origins of cardiac progenitors," Cell Stem Cell, vol. 2, no. 4, pp. 320-331, 2008.

[178] C. L. Mummery, J. Zhang, E. S. Ng, D. A. Elliott, A. G. Elefanty, and T. J. Kamp, "Differentiation of human embryonic stem cells and induced pluripotent stem cells to cardiomyocytes: a methods overview," Circulation Research, vol. 111, no. 3, pp. 344358, 2012.

[179] T. J. Nelson, A. Martinez-Fernandez, S. Yamada, C. PerezTerzic, Y. Ikeda, and A. Terzic, "Repair of acute myocardial infarction with induced pluripotent stem cells induced by human stemness factors," Circulation, vol. 120, no. 5, pp. 408416, 2009.

[180] L. Zwi-Dantsis, I. Huber, M. Habib et al., "Derivation and cardiomyocyte differentiation of induced pluripotent stem cells from heart failure patients," European Heart Journal, vol. 34, no. 21, pp. 1575-1586, 2013.

[181] P. W. Burridge and E. T. Zambidis, "Highly efficient directed differentiation of human induced pluripotent stem cells into cardiomyocytes," Methods in Molecular Biology, vol. 997, pp. 149-161, 2013.

[182] X. Lian, J. Zhang, S. M. Azarin et al., "Directed cardiomyocyte differentiation from human pluripotent stem cells by modulating Wnt/ $\beta$-catenin signaling under fully defined conditions," Nature Protocols, vol. 8, no. 1, pp. 162-175, 2013.

[183] X. Lian, C. Hsiao, G. Wilson et al., "Robust cardiomyocyte differentiation from human pluripotent stem cells via temporal modulation of canonical Wnt signaling," Proceedings of the National Academy of Sciences of the United States of America, vol. 109, no. 27, pp. E1848-E1857, 2012.

[184] Y. Shiba, S. Fernandes, W.-Z. Zhu et al., "Human ES-cell-derived cardiomyocytes electrically couple and suppress arrhythmias in injured hearts," Nature, vol. 489, no. 7415, pp. 322-325, 2012.

[185] M. Rubach, R. Adelmann, M. Haustein et al., "Mesenchymal stem cells and their conditioned medium improve integration of purified induced pluripotent stem cell-derived cardiomyocyte clusters into myocardial tissue," Stem Cells and Development, vol. 23, no. 6, pp. 643-653, 2014.

[186] L. Chang, M. Noseda, M. Higginson et al., "Differentiation of vascular smooth muscle cells from local precursors during embryonic and adult arteriogenesis requires Notch signaling," Proceedings of the National Academy of Sciences of the United States of America, vol. 109, no. 18, pp. 6993-6998, 2012.

[187] C. Cochain, K. M. Channon, and J.-S. Silvestre, "Angiogenesis in the infarcted myocardium," Antioxidants and Redox Signaling, vol. 18, no. 9, pp. 1100-1113, 2013.

[188] L. Carpenter, C. Carr, C. T. Yang, D. J. Stuckey, K. Clarke, and S. M. Watt, "Efficient differentiation of human induced pluripotent stem cells generates cardiac cells that provide protection following myocardial infarction in the rat," Stem Cells and Development, vol. 21, no. 6, pp. 977-986, 2012. 
[189] W.-H. Lai, J. C. Y. Ho, Y.-C. Chan et al., "Attenuation of hindlimb ischemia in mice with endothelial-like cells derived from different sources of human stem cells," PLOS ONE, vol. 8, no. 3, Article ID e57876, 2013.

[190] T. S. Park, I. Bhutto, L. Zimmerlin et al., "Vascular progenitors from cord blood-derived iPSC possess augmented capacity for regenerating ischemic retinal vasculature," Circulation, vol. 129, no. 3, pp. 359-372, 2013.

[191] A. J. Rufaihah, N. F. Huang, J. Kim et al., "Human induced pluripotent stem cell-derived endothelial cells exhibit functional heterogeneity," American Journal of Translational Research, vol. 5, no. 1, pp. 21-35, 2013.

[192] J. Fujita, Y. Itabashi, T. Seki et al., "Myocardial cell sheet therapy and cardiac function," American Journal of Physiology: Heart and Circulatory Physiology, vol. 303, no. 10, pp. H1169-H1182, 2012.

[193] H. Masumoto, T. Matsuo, K. Yamamizu et al., "Pluripotent stem cell-engineered cell sheets reassembled with defined cardiovascular populations ameliorate reduction in infarct heart function through cardiomyocyte-mediated neovascularization," Stem Cells, vol. 30, no. 6, pp. 1196-1205, 2012.

[194] M. Kawamura, S. Miyagawa, K. Miki et al., "Feasibility, safety, and therapeutic efficacy of human induced pluripotent stem cell-derived cardiomyocyte sheets in a porcine ischemic cardiomyopathy model," Circulation, vol. 126, no. 11, pp. S29-S37, 2012.

[195] B. Dai, W. Huang, M. Xu et al., "Reduced collagen deposition in infarcted myocardium facilitates induced pluripotent stem cell engraftment and angiomyogenesis for improvement of left ventricular function," Journal of the American College of Cardiology, vol. 58, no. 20, pp. 2118-2127, 2011.

[196] W. Huang, B. Dai, Z. Wen et al., "Molecular Strategy to Reduce In Vivo Collagen Barrier Promotes Entry of NCX1 Positive Inducible Pluripotent Stem Cells (iPSCNCX1+) into Ischemic (or Injured) Myocardium," PLoS ONE, vol. 8, no. 8, Article ID e70023, 2013.

[197] M. Kawamura, S. Miyagawa, S. Fukushima et al., “ Enhanced survival of transplanted human induced pluripotent stem cellderived cardiomyocytes by the combination of cell sheets with the pedicled omental flap technique in a porcine heart," Circulation, vol. 128, 1, pp. S87-S94, 2013.

[198] M. Halbach, G. Peinkofer, S. Baumgartner et al., "Electrophysiological integration and action potential properties of transplanted cardiomyocytes derived from induced pluripotent stem cells," Cardiovascular Research, vol. 100, no. 3, pp. 432-440, 2013.

[199] M. Ieda, J.-D. Fu, P. Delgado-Olguin et al., "Direct reprogramming of fibroblasts into functional cardiomyocytes by defined factors," Cell, vol. 142, no. 3, pp. 375-386, 2010.

[200] J. A. Efe, S. Hilcove, J. Kim et al., "Conversion of mouse fibroblasts into cardiomyocytes using a direct reprogramming strategy," Nature Cell Biology, vol. 13, no. 3, pp. 215-222, 2011.

[201] K. Inagawa, K. Miyamoto, H. Yamakawa et al., "Induction of cardiomyocyte-like cells in infarct hearts by gene transfer of Gata4, Mef2c, and Tbx5," Circulation Research, vol. 111, no. 9, pp. 1147-1156, 2012.

[202] L. Qian, Y. Huang, C. I. Spencer et al., "In vivo reprogramming of murine cardiac fibroblasts into induced cardiomyocytes," Nature, vol. 485, no. 7400, pp. 593-598, 2012.

[203] L. Qian, E. C. Berry, J.-D. Fu, M. Ieda, and D. Srivastava, "Reprogramming of mouse fibroblasts into cardiomyocyte-like cells in vitro," Nature Protocols, vol. 8, no. 6, pp. 1204-1215, 2013.
[204] K. Song, Y.-J. Nam, X. Luo et al., "Heart repair by reprogramming non-myocytes with cardiac transcription factors," Nature, vol. 485, no. 7400, pp. 599-604, 2012.

[205] J. X. Chen, M. Krane, M. A. Deutsch et al., "Inefficient reprogramming of fibroblasts into cardiomyocytes using Gata4, Mef2c, and Tbx5," Circulation Research, vol. 111, no. 1, pp. 50$55,2012$.

[206] M. Mathison, R. P. Gersch, A. Nasser et al., "In vivo cardiac cellular reprogramming efficacy is enhanced by angiogenic preconditioning of the infarcted myocardium with vascular endothelial growth factor," Journal of the American Heart Association, vol. 1, no. 6, 2012.

[207] R. Wada, N. Muraoka, K. Inagawa et al., "Induction of human cardiomyocyte-like cells from fibroblasts by defined factors," Proceedings of the National Academy of Sciences of the United States of America, vol. 110, no. 31, pp. 12667-12672, 2013.

[208] A. Bird, "Perceptions of epigenetics," Nature, vol. 447, no. 7143, pp. 396-398, 2007.

[209] Y.-J. Nam, K. Song, and E. N. Olson, "Heart repair by cardiac reprogramming," Nature Medicine, vol. 19, no. 4, pp. 413-415, 2013.

[210] L. Qian and D. Srivastava, “Direct cardiac reprogramming: from developmental biology to cardiac regeneration," Cardiovascular Research, vol. 113, no. 7, pp. 915-921, 2013.

[211] J. Chen, H. Liu, J. Liu et al., "H3K9 methylation is a barrier during somatic cell reprogramming into iPSCs," Nature Genetics, vol. 45, no. 1, pp. 34-42, 2013.

[212] M. Vecellio, V. Meraviglia, S. Nanni et al., "In vitro epigenetic reprogramming of human cardiac mesenchymal stromal cells into functionally competent cardiovascular precursors," PLoS ONE, vol. 7, no. 12, Article ID e51694, 2012.

[213] A. Margariti, B. Winkler, E. Karamariti et al., "Direct reprogramming of fibroblasts into endothelial cells capable of angiogenesis and reendothelialization in tissue-engineered vessels," Proceedings of the National Academy of Sciences of the United States of America, vol. 109, no. 34, pp. 13793-13798, 2012.

[214] J. Li, N. F. Huang, J. Zou et al., "Conversion of human fibroblasts to functional endothelial cells by defined factors," Arteriosclerosis, Thrombosis, and Vascular Biology, vol. 33, no. 6, pp. 1366-1375, 2013.

[215] T. M. Jayawardena, B. Egemnazarov, E. A. Finch et al., "MicroRNA-mediated in vitro and in vivo direct reprogramming of cardiac fibroblasts to cardiomyocytes," Circulation Research, vol. 110, no. 11, pp. 1465-1473, 2012.

[216] D. A. Robinton and G. Q. Daley, "The promise of induced pluripotent stem cells in research and therapy," Nature, vol. 481, no. 7381, pp. 295-305, 2012.

[217] F. T. Merkle and K. Eggan, "Modeling human disease with pluripotent stem cells: from genome association to function," Cell Stem Cell, vol. 12, no. 6, pp. 656-668, 2013.

[218] L. M. R. Ferreira and M. A. Mostajo-Radji, "How induced pluripotent stem cells are redefining personalized medicine," Gene, vol. 520, no. 1, pp. 1-6, 2013.

[219] M. A. G. Van Der Heyden and M. K. B. Jonsson, "Personalized medicine and the role of induced pluripotent stem cells," Cardiovascular Research, vol. 95, no. 4, pp. 395-396, 2012.

[220] S. J. Engle and D. Puppala, "Integrating human pluripotent stem cells into drug development," Cell Stem Cell, vol. 12, no. 6, pp. 699-712, 2013.

[221] J. T. Dimos, K. T. Rodolfa, K. K. Niakan et al., "Induced pluripotent stem cells generated from patients with ALS can be 
differentiated into motor neurons," Science, vol. 321, no. 5893, pp. 1218-1221, 2008.

[222] I.-H. Park, N. Arora, H. Huo et al., "Disease-Specific Induced Pluripotent Stem Cells," Cell, vol. 134, no. 5, pp. 877-886, 2008.

[223] A. D. Ebert, J. Yu, F. F. Rose Jr. et al., "Induced pluripotent stem cells from a spinal muscular atrophy patient," Nature, vol. 457, no. 7227, pp. 277-280, 2009.

[224] M. Grskovic, A. Javaherian, B. Strulovici, and G. Q. Daley, "Induced pluripotent stem cells-opportunities for disease modelling and drug discovery," Nature Reviews Drug Discovery, vol. 10, no. 12, pp. 915-929, 2011.

[225] C. Dambrot, R. Passier, D. Atsma, and C. L. Mummery, "Cardiomyocyte differentiation of pluripotent stem cells and their use as cardiac disease models," Biochemical Journal, vol. 434, no. 1, pp. 25-35, 2011.

[226] X. Carvajal-Vergara, A. Sevilla, S. L. Dsouza et al., "Patientspecific induced pluripotent stem-cell-derived models of LEOPARD syndrome," Nature, vol. 465, no. 7299, pp. 808-812, 2010.

[227] A. Moretti, M. Bellin, A. Welling et al., "Patient-specific induced pluripotent stem-cell models for long-QT syndrome," The New England Journal of Medicine, vol. 363, no. 15, pp. 1397-1409, 2010.

[228] I. Itzhaki, L. Maizels, I. Huber et al., "Modelling the long QT syndrome with induced pluripotent stem cells," Nature, vol. 471, no. 7337, pp. 225-230, 2011.

[229] M. Yazawa, B. Hsueh, X. Jia et al., "Using induced pluripotent stem cells to investigate cardiac phenotypes in Timothy syndrome," Nature, vol. 471, no. 7337, pp. 230-236, 2011.

[230] F. Lan, A. S. Lee, P. Liang et al., "Abnormal calcium handling properties underlie familial hypertrophic cardiomyopathy pathology in patient-specific induced pluripotent stem cells," Cell Stem Cell, vol. 12, no. 1, pp. 101-113, 2013.

[231] N. Sun, M. Yazawa, J. Liu et al., "Patient-specific induced pluripotent stem cells as a model for familial dilated cardiomyopathy," Science Translational Medicine, vol. 4, no. 130, Article ID 130ra47, pp. 130r-147r, 2012.

[232] D. Ma, H. Wei, J. Lu et al., "Generation of patient-specific induced pluripotent stem cell-derived cardiomyocytes as a cellular model of arrhythmogenic right ventricular cardiomyopathy," European Heart Journal, vol. 34, no. 15, pp. 1122-1133, 2013.

[233] R. P. Davis, S. Casini, C. W. Van Den Berg et al., "Cardiomyocytes derived from pluripotent stem cells recapitulate electrophysiological characteristics of an overlap syndrome of cardiac sodium channel disease," Circulation, vol. 125, no. 25, pp. 3079-3091, 2012.

[234] D. Malan, S. Friedrichs, B. K. Fleischmann, and P. Sasse, "Cardiomyocytes obtained from induced pluripotent stem cells with Long-QT syndrome 3 recapitulate typical disease-specific features in vitro," Circulation Research, vol. 109, no. 8, pp. 841847, 2011.

[235] M. Bellin, S. Casini, R. P. Davis et al., "Isogenic human pluripotent stem cell pairs reveal the role of a $\mathrm{KCNH} 2$ mutation in long-QT syndrome," The EMBO Journal, vol. 32, no. 24, pp. 3161-3175, 2013.

[236] D. Sinnecker, A. Goedel, K.-L. Laugwitz, and A. Moretti, "Induced pluripotent stem cell-derived cardiomyocytes: a versatile tool for arrhythmia research," Circulation Research, vol. 112, no. 6, pp. 961-968, 2013.

[237] C. B. Jung, A. Moretti, M. Mederos y Schnitzler et al., "Dantrolene rescues arrhythmogenic RYR2 defect in a patient-specific stem cell model of catecholaminergic polymorphic ventricular tachycardia," EMBO Molecular Medicine, vol. 4, no. 3, pp. 180191, 2012.

[238] H. Zhou, M. Xu, Q. Huang et al., "Genome-scale RNAi screen for host factors required for HIV replication," Cell Host and Microbe, vol. 4, no. 5, pp. 495-504, 2008.

[239] C. W. Scott, M. F. Peters, and Y. P. Dragan, "Human induced pluripotent stem cells and their use in drug discovery for toxicity testing," Toxicology Letters, vol. 219, no. 1, pp. 49-58, 2013.

[240] J. C. Davila, G. G. Cezar, M. Thiede, S. Strom, T. Miki, and J. Trosko, "Use and application of stem cells in toxicology," Toxicological Sciences, vol. 79, no. 2, pp. 214-223, 2004.

[241] T. Seki, S. Yuasa, M. Oda et al., "Generation of induced pluripotent stem cells from human terminally differentiated circulating t cells," Cell Stem Cell, vol. 7, no. 1, pp. 11-13, 2010.

[242] P. Liang, F. Lan, A. S. Lee et al., "Drug screening using a library of human induced pluripotent stem cell-derived cardiomyocytes reveals disease-specific patterns of cardiotoxicity," Circulation, vol. 127, no. 16, pp. 1677-1691, 2013.

[243] H. Lal, K. L. Kolaja, and T. Force, "Cancer genetics and the cardiotoxicity of the therapeutics," Journal of the American College of Cardiology, vol. 61, no. 3, pp. 267-274, 2013.

[244] M. Mercola, A. Colas, and E. Willems, "Induced pluripotent stem cells in cardiovascular drug discovery," Circulation Research, vol. 112, no. 3, pp. 534-548, 2013.

[245] H. Kamao, M. Mandai, S. Okamoto et al., "Characterization of human induced pluripotent stem cell-derived retinal pigment epithelium cell sheets aiming for clinical application," Stem Cell Reports, vol. 2, no. 2, pp. 205-218, 2014.

[246] D. Cyranoski, "Stem cells cruise to clinic," Nature, vol. 494, no. 7438, p. 413, 2013.

[247] F. Hattori, H. Chen, H. Yamashita et al., "Nongenetic method for purifying stem cell-derived cardiomyocytes," Nature Methods, vol. 7, no. 1, pp. 61-66, 2010.

[248] H. Uosaki, H. Fukushima, A. Takeuchi et al., "Efficient and scalable purification of cardiomyocytes from human embryonic and induced pluripotent stem cells by VCAM1 surface expression," PLoS ONE, vol. 6, no. 8, Article ID e23657, 2011.

[249] D. A. Elliott, S. R. Braam, K. Koutsis et al., "NKX2 - $5^{e G F P L W}$ hESCs for isolation of human cardiac progenitors and cardiomyocytes," Nature Methods, vol. 8, no. 12, pp. 1037-1043, 2011.

[250] L. W. Van Laake, L. Qian, P. Cheng et al., "Reporter-based isolation of induced pluripotent stem cell-and embryonic stem cell-derived cardiac progenitors reveals limited gene expression variance," Circulation Research, vol. 107, no. 3, pp. 340-347, 2010.

[251] G. Blin, D. Nury, S. Stefanovic et al., "A purified population of multipotent cardiovascular progenitors derived from primate pluripotent stem cells engrafts in postmyocardial infarcted nonhuman primates," The Journal of Clinical Investigation, vol. 120, no. 4, pp. 1125-1139, 2010.

[252] K. Ban, B. Wile, S. Kim et al., "Purification of cardiomyocytes from differentiating pluripotent stem cells using molecular beacons that target cardiomyocyte-specific mRNA," Circulation, vol. 128, no. 17, pp. 1897-1909, 2013.

[253] S. Tohyama, F. Hattori, M. Sano et al., "Distinct metabolic flow enables large-scale purification of mouse and human pluripotent stem cell-derived cardiomyocytes," Cell Stem Cell, vol. 12, no. 1, pp. 127-137, 2013.

[254] U. Ben-David and N. Benvenisty, "The tumorigenicity of human embryonic and induced pluripotent stem cells," Nature Reviews Cancer, vol. 11, no. 4, pp. 268-277, 2011. 
[255] K. C. Wollert, G. P. Meyer, J. Lotz et al., "Intracoronary autologous bone-marrow cell transfer after myocardial infarction: the BOOST randomised controlled clinical trial," The Lancet, vol. 364, no. 9429, pp. 141-148, 2004.

[256] Y. Mayshar, U. Ben-David, N. Lavon et al., "Identification and classification of chromosomal aberrations in human induced pluripotent stem cells," Cell Stem Cell, vol. 7, no. 4, pp. 521-531, 2010.

[257] E. Vanneste, T. Voet, C. Le Caignec et al., "Chromosome instability is common in human cleavage-stage embryos," Nature Medicine, vol. 15, no. 5, pp. 577-583, 2009.

[258] N. Hyka-Nouspikel, J. Desmarais, P. J. Gokhale et al., "Deficient DNA damage response and cell cycle checkpoints lead to accumulation of point mutations in human embryonic stem cells," Stem Cells, vol. 30, no. 9, pp. 1901-1910, 2012.

[259] M. X. Doss, J. M. Di Diego, R. J. Goodrow et al., "Maximum diastolic potential of human induced pluripotent stem cellderived cardiomyocytes depends critically on IKr," PLoS ONE, vol. 7, no. 7, Article ID e40288, 2012.

[260] A. Kuzmenkin, H. Liang, G. Xu et al., "Functional characterization of cardiomyocytes derived from murine induced pluripotent stem cells in vitro," FASEB Journal, vol. 23, no. 12, pp. 4168-4180, 2009.

[261] J. M. Cordeiro, V. V. Nesterenko, S. Sicouri et al., "Identification and characterization of a transient outward $\mathrm{K}^{+}$current in human induced pluripotent stem cell-derived cardiomyocytes," Journal of Molecular and Cellular Cardiology, vol. 60, no. 1, pp. 36-46, 2013.

[262] C. Y. Ivashchenko, G. C. Pipes, I. M. Lozinskaya et al., "Humaninduced pluripotent stem cell-derived cardiomyocytes exhibit temporal changes in phenotype," American Journal of Physiology, vol. 305, no. 6, pp. H913-H922, 2013.

[263] P. Jakob and U. Landmesser, "Role of microRNAs in stem/progenitor cells and cardiovascular repair," Cardiovascular Research, vol. 93, no. 4, pp. 614-622, 2012.

[264] M. Quattrocelli, G. Palazzolo, I. Agnolin et al., "Synthetic sulfonyl-hydrazone-1 positively regulates cardiomyogenic microRNA expression and cardiomyocyte differentiation of induced pluripotent stem cells," Journal of Cellular Biochemistry, vol. 112, no. 8, pp. 2006-2014, 2011.

[265] N. Cao, Z. Liu, Z. Chen et al., "Ascorbic acid enhances the cardiac differentiation of induced pluripotent stem cells through promoting the proliferation of cardiac progenitor cells," Cell Research, vol. 22, no. 1, pp. 219-236, 2012.

[266] S. S. Nunes, J. W. Miklas, J. Liu et al., "Biowire: a platform for maturation of human pluripotent stem cell-derived cardiomyocytes," Nature Methods, vol. 10, no. 8, pp. 781-787, 2013.

[267] A. Nsair, K. Schenke-Layland, B. van Handel et al., "Characterization and therapeutic potential of induced pluripotent stem cell-derived cardiovascular progenitor cells," PLoS ONE, vol. 7, no. 10, Article ID e45603, 2012.

[268] P. E. De Almeida, J. D. Ransohoff, A. Nahid, and J. C. Wu, "Immunogenicity of pluripotent stem cells and their derivatives," Circulation Research, vol. 112, no. 3, pp. 549-561, 2013.

[269] T. Zhao, Z.-N. Zhang, Z. Rong, and Y. Xu, "Immunogenicity of induced pluripotent stem cells," Nature, vol. 474, no. 7350, pp. 212-216, 2011.

[270] Z. Liu, X. Wen, H. Wang et al., "Molecular imaging of induced pluripotent stem cell immunogenicity with in vivo development in ischemic myocardium," PLoS ONE, vol. 8, no. 6, Article ID e66369, 2013.
[271] S. Kaneko and S. Yamanaka, "To be immunogenic, or not to be: that's the iPSC question," Cell Stem Cell, vol. 12, no. 4, pp. 385386, 2013.

[272] R. Araki, M. Uda, Y. Hoki et al., "Negligible immunogenicity of terminally differentiated cells derived from induced pluripotent or embryonic stem cells," Nature, vol. 494, no. 7435, pp. 100-104, 2013.

[273] P. Guha, J. W. Morgan, G. Mostoslavsky, N. P. Rodrigues, and A. S. Boyd, "Lack of immune response to differentiated cells derived from syngeneic induced pluripotent stem cells," Cell Stem Cell, vol. 12, no. 4, pp. 407-412, 2013.

[274] K. M. Dhodapkar, D. Feldman, P. Matthews et al., "Natural immunity to pluripotency antigen OCT4 in humans," Proceedings of the National Academy of Sciences of the United States of America, vol. 107, no. 19, pp. 8718-8723, 2010.

[275] M. Rao, L. Ahrlund-Richter, and D. S. Kaufman, "Concise review: cord blood banking, transplantation and induced pluripotent stem cell: success and opportunities," Stem Cells, vol. 30, no. 1, pp. 55-60, 2012.

[276] C. J. Taylor, E. M. Bolton, and J. A. Bradley, "Immunological considerations for embryonic and induced pluripotent stem cell banking," Philosophical Transactions of the Royal Society B: Biological Sciences, vol. 366, no. 1575, pp. 2312-2322, 2011.

[277] K. Okita, Y. Matsumura, Y. Sato et al., "A more efficient method to generate integration-free human iPS cells," Nature Methods, vol. 8, no. 5, pp. 409-412, 2011.

[278] C. J. Taylor, S. Peacock, A. N. Chaudhry, J. A. Bradley, and E. M. Bolton, "Generating an iPSC bank for HLA-matched tissue transplantation based on known donor and recipient hla types," Cell Stem Cell, vol. 11, no. 2, pp. 147-152, 2012.

[279] J. I. Pearl, A. S. Lee, D. B. Leveson-Gower et al., "Short-term immunosuppression promotes engraftment of embryonic and induced pluripotent stem cells," Cell Stem Cell, vol. 8, no. 3, pp. 309-317, 2011. 

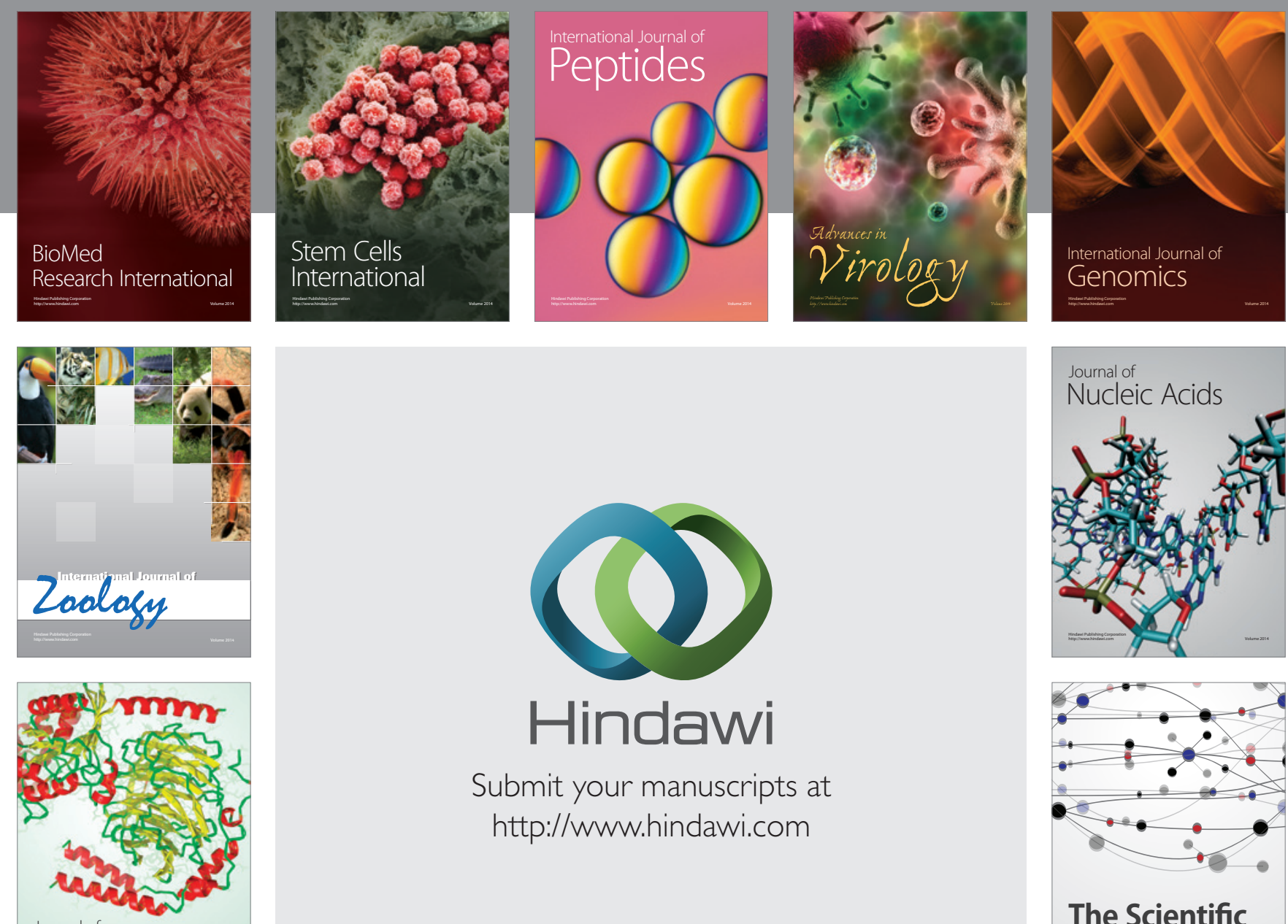

Submit your manuscripts at

http://www.hindawi.com

Journal of
Signal Transduction
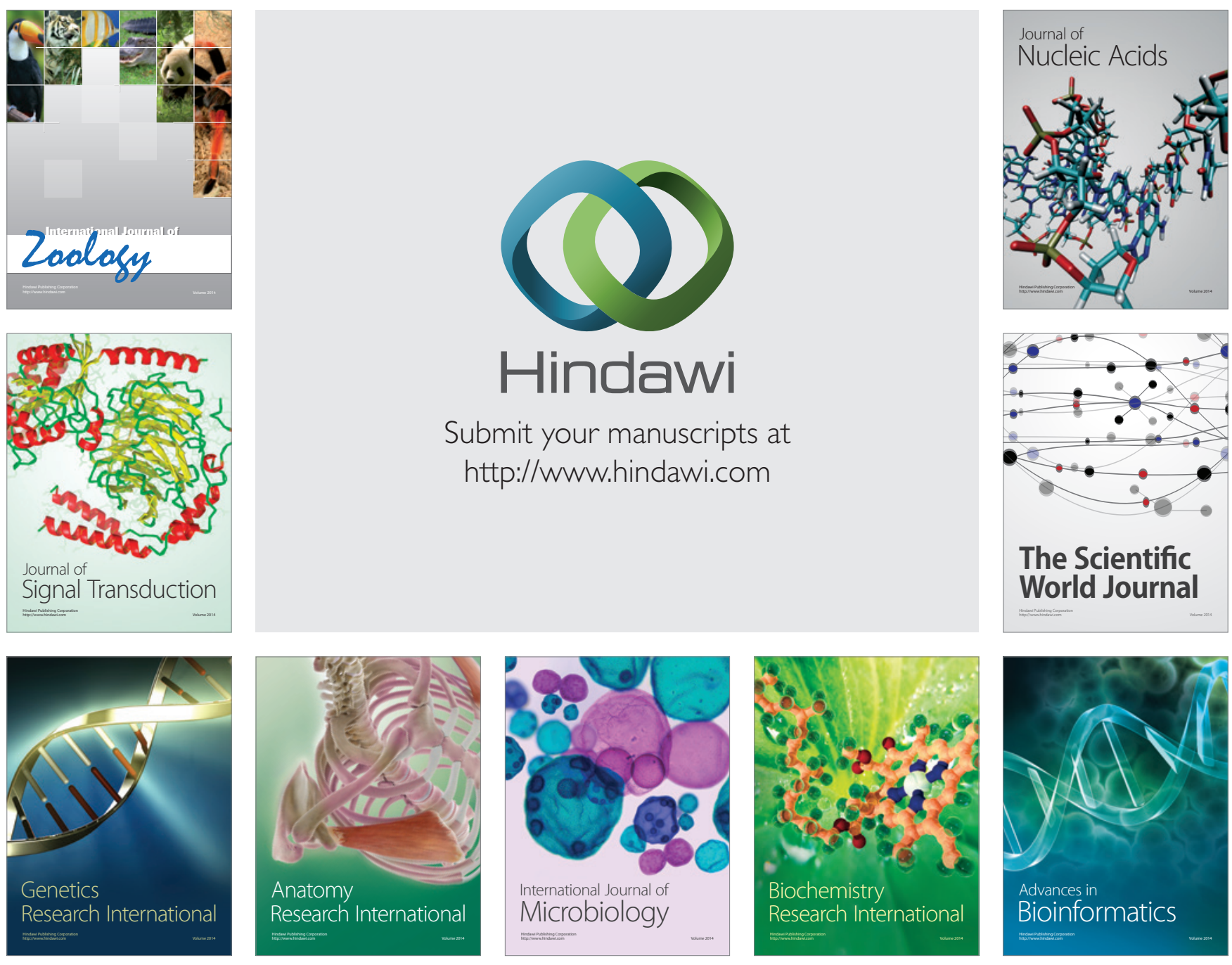

The Scientific World Journal
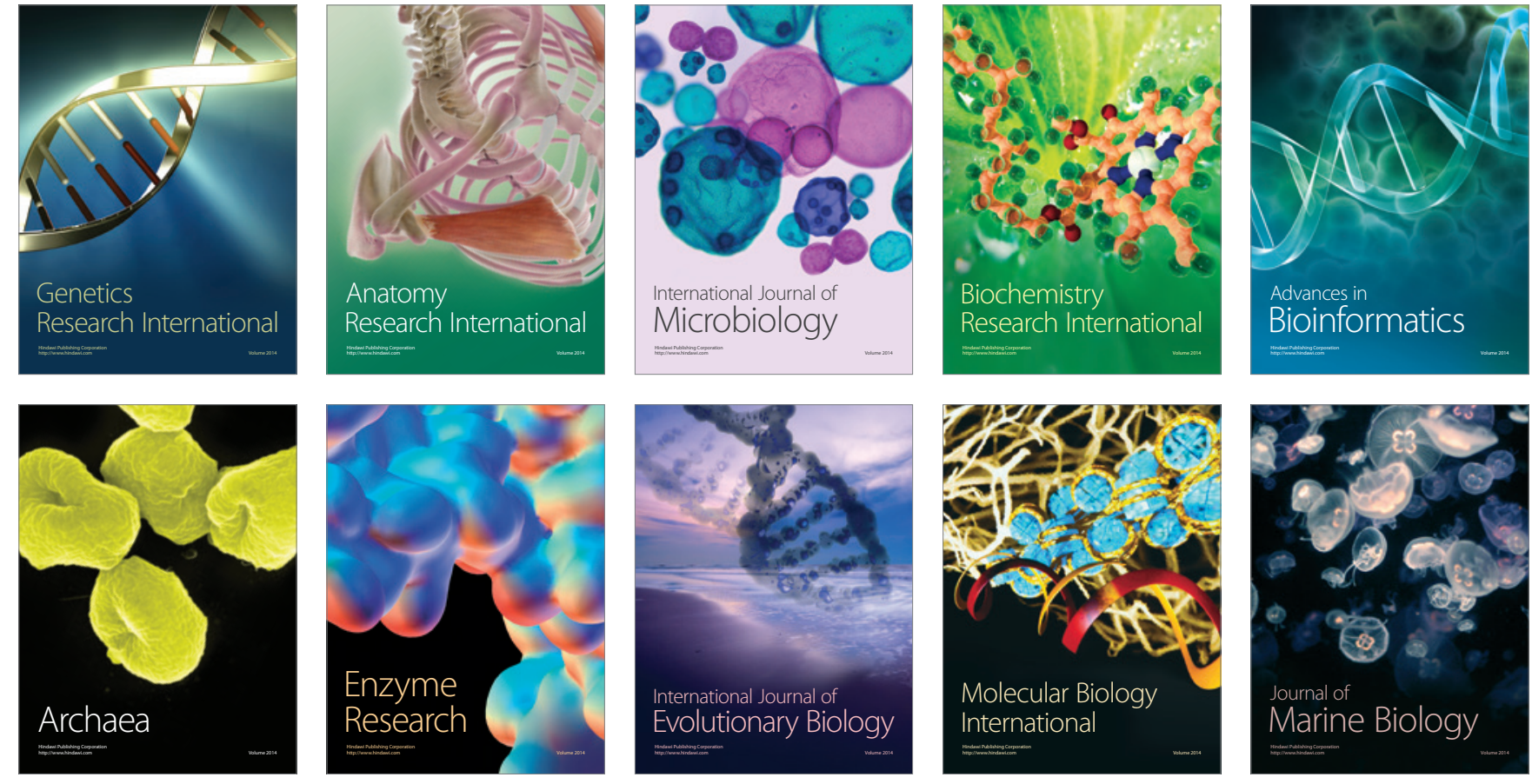